\title{
Identification and Antibiotic Profiling of Wohlfahrtiimonas chitiniclastica, an Underestimated Human Pathogen
}

\author{
Anna Kopf ${ }^{1}$, Boyke Bunk', Sina M. Coldewey ${ }^{3,4}$, Florian Gunzer ${ }^{5}$, Thomas Riedel ${ }^{2,6}$ and \\ Percy Schröttner ${ }^{1 *}$ \\ ${ }^{1}$ Institute of Medical Microbiology and Virology, University Hospital Carl Gustav Carus, Dresden, Germany, ${ }^{2}$ Leibniz Institute \\ DSMZ-German Collection of Microorganisms and Cell Cultures GmbH, Braunschweig, Germany, ${ }^{3}$ Clinic for Anaesthesiology \\ and Intensive Care Medicine, Jena University Hospital, Jena, Germany, ${ }^{4}$ Septomics Research Center, Jena University \\ Hospital, Jena, Germany, ${ }^{5}$ Department of Hospital Infection Control, University Hospital Carl Gustav Carus, Dresden, \\ Germany, ${ }^{6}$ German Center for Infection Research (DZIF), Partner Site Hannover-Braunschweig, Braunschweig, Germany
}

OPEN ACCESS

Edited by: Fabian Cieplik,

University Medical Center Regensburg, Germany

Reviewed by: Aaron Lynne,

Sam Houston State University, United States

Tim Maisch,

University of Regensburg, Germany

${ }^{*}$ Correspondence:

Percy Schröttner percy.schroettner@tu-dresden.de

Specialty section:

This article was submitted to Antimicrobials, Resistance

and Chemotherapy,

a section of the journa

Frontiers in Microbiology

Received: 21 May 2021

Accepted: 27 August 2021 Published: 22 September 2021

Citation:

Kopf A, Bunk B, Coldewey SM, Gunzer $F$, Riedel $T$ and Schröttner $P$ (2021) Identification and Antibiotic

Profiling of Wohlfahrtiimonas chitiniclastica, an Underestimated

Human Pathogen.

Front. Microbiol. 12:712775. doi: 10.3389/fmicb.2021.712775
In the past 12 years, several case reports have clearly demonstrated that Wohlfahrtiimonas chitiniclastica is capable of causing sepsis and bacteremia in humans. However, since most clinicians are not familiar with this species, little is known about its pathogenicity and treatment options while it is as rare but underestimated human pathogen. Therefore, a larger strain collection is required so that methods can be identified that are most suitable to obtain rapid and reliable identification. Moreover, the antimicrobial resistance profile needs to be elucidated in order to explore possible treatment options. Over a period of 6 years, we therefore have collected a total of $14 \mathrm{~W}$. chitiniclastica isolates in routine diagnostics, which now served as the basis for a comprehensive characterization with respect to identification and antibiotic profiling. We compared the accuracy and convenience of several identification techniques in which MALDI-TOF MS and sequencing of the 16S rRNA gene have proven to be suitable for identification of $W$. chitiniclastica. In addition, whole genome sequencing (WGS)-based digital DNA-DNA hybridization ( $\mathrm{dDDH}$ ) was used as a reference method for strain identification, and surprised with the detection of a novel W. chitiniclastica subspecies. A combination of in silico and in vitro analyses revealed a first insight into the antimicrobial resistance profile and the molecular basis of antimicrobial resistance. Based on our findings, trimethoprim/sulfamethoxazole, levofloxacin, and cephalosporins (e.g., ceftazidime) may be the best antibiotics to use in order to treat infections caused by $W$. chitiniclastica, while resistance to fosfomycin, amikacin and tobramycin is observed.

Keywords: Wohlfahrtiimonas chitiniclastica, antibiotic profiling, MALDI-TOF MS, 16S rRNA, primer, VITEK 2, digital DNA-DNA hybridization

\section{INTRODUCTION}

The gammaproteobacterium Wohlfahrtiimonas chitiniclastica has first been isolated from larvae of Wohlfahrtia magnifica (Tóth et al., 2008), an obligatory parasitic fly that causes myiasis by depositing eggs and larvae in mammalian wounds both in animals and humans (Robbins and Khachemoune, 2010). Bacteria belonging to this species are described as Gram-negative, strictly aerobic, and non-motile rods. Furthermore, the organism is catalase and oxidase positive, while biochemical tests for urease, indole, and $\mathrm{H}_{2} \mathrm{~S}$ are negative (Tóth et al., 2008; Schröttner et al., 2017). 
They are also noted to have strong chitinase activity, which may be an indicator for a symbiotic relationship with its host fly while playing an important role in metamorphosis (Schröttner et al., 2017; Snyder et al., 2020).

In April 2021, GenBank (Benson et al., 2013) lists 12 genomes of $W$. chitiniclastica strains while three draft genome reports were published (Cao et al., 2013; Zhou et al., 2016; Matos et al., 2019). The strains are described to be susceptible to the majority of known antibiotics with the exception of fosfomycin (Schröttner et al., 2017; Matos et al., 2019). First genome annotations revealed genes coding for macrolide-specific efflux pumps (macA and $m a c B$ ) (Matos et al., 2019) and a bla $a_{V E B-1}$ gene cassette which confers resistance to ceftazidime, ampicillin, and tetracycline (Zhou et al., 2016). However, in-depth analysis is still required to generate a comprehensive antimicrobial resistance profile as the available antimicrobial susceptibility data are mostly based on case reports and preliminary genome annotations (Zhou et al., 2016; Schröttner et al., 2017; Matos et al., 2019).

Originally isolated from a homogenate of fly larvae, there is increasing evidence that $W$. chitiniclastica may be the cause of several diseases in humans. Although the pathogenesis of $W$. chitiniclastica is not yet fully understood, the bacterium is expected to enter traumatic skin lesions through fly larvae, resulting in severe myiasis and/or wound contamination (Robbins and Khachemoune, 2010; Thaiwong et al., 2014; Schröttner et al., 2017). To date, 23 human case reports from 18 countries across the globe have been published (Table 1 and Figure 1) indicating $W$. chitiniclastica to be associated with humans sepsis and bacteremia. For example, Almuzara et al. (2011) reported the first case of fulminant sepsis with fatal outcome and Campisi et al. (2015) observed W. chitiniclastica bacteremia associated with myiasis, to name but a few. However, since most clinicians are not familiar with this species, it can be assumed that $W$. chitiniclastica has hardly been recognized as a possible cause while it has recently been described as a new underestimated human pathogen (Schröttner et al., 2017). Therefore, it is necessary to initiate systematic investigations to gain more knowledge about its virulence and treatment options. For this reason, first methods need to be identified that are most suitable to obtain a fast, reliable and robust species identification. Moreover, we need to shed light on the antimicrobial resistance profile to gain knowledge about primary resistances in order to treat infections successfully. In this study, we therefore compared the accuracy of several routine methods of bacterial identification and performed antimicrobial susceptibility testing of 14 isolates collected from clinical samples. Additionally, we conducted whole genome data to elucidate the molecular basis of antimicrobial resistance and to confirm correct species designation.

\section{MATERIALS AND METHODS}

\section{Collection of W. chitiniclastica Strains}

Over a period of 6 years, a total of $14 \mathrm{~W}$. chitiniclastica strains have been collected in routine diagnostics (see Table 2). All isolates were recovered exclusively from diagnostic cultures analyzed at the Institute for Medical Microbiology and Virology,
University Hospital Carl Gustav Carus (Dresden, Germany). Prior to this publication the isolates DSM 100374, DSM 100374, DSM 100676, and DSM 100917 were briefly described as part of a review article (Schröttner et al., 2017); however a thorough analysis has not been performed. Subsequently, all strains were collected and stored in Pro-Lab Diagnostics ${ }^{\mathrm{TM}}$ Microbank $^{\mathrm{TM}}$ (Fisher Scientific, Schwerte, Germany). The bacteria were additionally deposited at the "Open Collection" of the Leibniz Institute DSMZ-German Collection of Microorganisms and Cell Cultures (Braunschweig, Germany). The type strain DSM $18708^{\mathrm{T}}$ was purchased from the DSMZ and included as reference strain in this study.

\section{Identification of W. chitiniclastica Using VITEK 2}

Frozen colonies were grown on Colombia blood agar plates (bioMérieux, Nürtingen, Germany) for $24 \mathrm{~h}$ at $37^{\circ} \mathrm{C}$. A single colony from each isolate was picked and transferred to a new Colombia blood agar plate. After another incubation period of $24 \mathrm{~h}$ at $37^{\circ} \mathrm{C}$, the colonies were suspended in a solution of $3 \mathrm{ml}$ of $0.45 \%$ saline. A turbidity of $0.5-0.63 \mathrm{McFarland}$ standard using VITEK DensiCHEK Plus (bioMérieux, Nürtingen, Germany) was established. Bacteria were identified with a VITEK 2 system (bioMérieux, Nürtingen, Germany) using GN ID cards (for analysis of gram-negative bacteria) as described in a previous study (Schröttner et al., 2014). Results are displayed in Table 3 and Supplementary Table 5.

\section{Identification of W. chitiniclastica Using MALDI-TOF MS}

Identification of the strain collection of $W$. chitiniclastica using MALDI TOF MS was performed as previously described (Schröttner et al., 2014, 2016). In brief, strains were grown on Colombia blood agar plates for $24 \mathrm{~h}$ at $37^{\circ} \mathrm{C}$. Single colonies were picked and plated on a 96-well steel target. Bacteria were dried on a laboratory workbench for $10 \mathrm{~min}$ and then overlaid with a $1 \mu l$ matrix ( $\alpha$-Cyano-4-hydroxycinnamic acid, Bruker Daltonik, Bremen, Germany) dissolved in an organic solvent. Subsequently, MALDI-TOF MS analyses were performed using flexControl software 3.1 (Bruker Daltonik, Bremen, Germany) following the manufacturer's guidelines. Results are displayed in Table 3.

\section{Identification of W. chitiniclastica Using 16S rRNA Gene Analysis}

Prior to PCR amplification, the performance of different primer pairs was evaluated in silico using TestPrime (Klindworth et al., 2012) ${ }^{1}$ based on the SILVA Reference database (release SSURef 138 NR) (Quast et al., 2013). PCR was carried out using the following primer pair combinations: (i) TPU-1 (5'-AGA GTT TGA TCM TGG CTC AG-3') and RTU-4 (5'-TAC CAG GGT ATC TAA TCC TGT T-3') (Funke et al., 2004); and (ii) 27F (5'-AGA GTT TGA TCM TGG CTC AG-3') (Hongoh et al., 2003) and 1492R (5'-TAC CAG GGT ATC TAA TCC TGT T-3') (Weisburg et al., 1991). 16S rRNA gene amplification was performed as previously described (Schröttner et al., 2014,

${ }^{1}$ https://www.arb-silva.de/search/testprime/ 
TABLE 1 | Current overview of cases of human infection and colonization with W. chitiniclastica.

\begin{tabular}{|c|c|c|c|c|c|c|c|c|c|c|}
\hline Case & Year & Age & Gender & Region & $\begin{array}{c}\text { Underlying } \\
\text { disease(s)/reason for } \\
\text { hospital admission }\end{array}$ & $\begin{array}{l}\text { Social } \\
\text { conditions }\end{array}$ & $\begin{array}{c}\text { Insect } \\
\text { larvae/infected } \\
\text { wounds }\end{array}$ & $\begin{array}{l}\text { Antibiotic } \\
\text { treatment }\end{array}$ & Outcome & References \\
\hline 1 & 2009 & 60 & $f$ & $\begin{array}{l}\text { Marseille, } \\
\text { France }\end{array}$ & Fatigue & $\begin{array}{l}\text { Homeless, poor } \\
\text { hygienic } \\
\text { conditions, } \\
\text { alcoholism }\end{array}$ & Positive & Ceftriaxone & Survived & $\begin{array}{l}\text { Rebaudet et al., } \\
2009\end{array}$ \\
\hline 2 & 2011 & 70 & $\mathrm{~m}$ & $\begin{array}{l}\text { Buenos Aires, } \\
\text { Argentina }\end{array}$ & $\begin{array}{l}\text { Occlusive peripheral } \\
\text { arteriopathy of the lower } \\
\text { limbs/sensory impairment }\end{array}$ & $\begin{array}{l}\text { Homeless, } \\
\text { history of } \\
\text { alcoholism and } \\
\text { smoking }\end{array}$ & Negative & $\begin{array}{l}\text { Ciprofloxacin, } \\
\text { Ampicillin, } \\
\text { Ceftazidime, } \\
\text { Amikacin }\end{array}$ & Fatal & $\begin{array}{c}\text { Almuzara et al., } \\
2011\end{array}$ \\
\hline 3 & 2015 & 82 & f & $\begin{array}{l}\text { Guildford, } \\
\text { United Kingdom }\end{array}$ & $\begin{array}{l}\text { Recurrent falls, hypertension, } \\
\text { chronic kidney disease, } \\
\text { ischemic heart disease, } \\
\text { hypercholesterolemia, } \\
\text { osteoarthritis/found } \\
\text { unconscious }\end{array}$ & NP & Positive & $\begin{array}{l}\text { Cefuroxime, } \\
\text { Clarithromycin, } \\
\text { Flucloxacillin }\end{array}$ & Survived & $\begin{array}{l}\text { Campisi et al., } \\
2015\end{array}$ \\
\hline 4 & 2015 & 26 & $\mathrm{~m}$ & $\begin{array}{l}\text { Salt Lake City, } \\
\text { United States }\end{array}$ & $\begin{array}{c}\text { Morbid obesity, lymphoedema, } \\
\text { cellulitis/progressive } \\
\text { gangrenous changes }\end{array}$ & NP & NP & Cefpodoxime & Survived & $\begin{array}{l}\text { de Dios et al., } \\
2015\end{array}$ \\
\hline 5 & 2015 & 64 & $\mathrm{~m}$ & Tartu, Estonia & $\begin{array}{l}\text { Gangrene in distal parts of the } \\
\text { legs and amputation of the } \\
\text { feet/admission due to an } \\
\text { accident }\end{array}$ & Alcoholism & NP & $\begin{array}{l}\text { Amoxicillin/ } \\
\text { Clavulanate }\end{array}$ & Survived & $\begin{array}{l}\text { Kõljalg et al., } \\
2015\end{array}$ \\
\hline 6 & 2015 & 43 & $\mathrm{~m}$ & $\begin{array}{l}\text { Trivandrum, } \\
\text { India }\end{array}$ & $\begin{array}{l}\text { Diabetes, deep ulcer, cellulitis, } \\
\text { gangrene/progressing } \\
\text { gangrenous changes }\end{array}$ & $\begin{array}{l}\text { Alcoholism, } \\
\text { smoking }\end{array}$ & NP & $\begin{array}{l}\text { Cefoperazone/ } \\
\text { Sulbactam, } \\
\text { Cefpodoxime }\end{array}$ & Survived & $\begin{array}{l}\text { Suryalatha } \\
\text { et al., } 2015\end{array}$ \\
\hline 7 & 2016 & 17 & $\mathrm{~m}$ & $\begin{array}{l}\text { Cape Town, } \\
\text { South Africa }\end{array}$ & $\begin{array}{l}\text { Soft-tissue infection due to an } \\
\text { accident }\end{array}$ & $\begin{array}{l}\text { Good hygienic } \\
\text { conditions }\end{array}$ & Negative & Ceftriaxone & Survived & $\begin{array}{l}\text { Hoffmann et al., } \\
2016\end{array}$ \\
\hline 8 & 2016 & 72 & $\mathrm{~m}$ & $\begin{array}{c}\text { Hawaii, } \\
\text { United States }\end{array}$ & Stroke, found unconscious & $\begin{array}{l}\text { Poor hygienic } \\
\text { conditions }\end{array}$ & Positive & $\begin{array}{l}\text { Piperacillin/ } \\
\text { Tazobactam, } \\
\text { Clindamycin, } \\
\text { Vancomycin }\end{array}$ & Fatal & $\begin{array}{l}\text { Nogi et al., } \\
2016\end{array}$ \\
\hline 9 & 2016 & 69 & $f$ & $\begin{array}{c}\text { Hawaii, } \\
\text { United States }\end{array}$ & $\begin{array}{c}\text { Ruptured cerebral aneurysm } \\
\text { and right hemiparesis/sacral } \\
\text { pain and painful urination }\end{array}$ & $\begin{array}{l}\text { Homeless, poor } \\
\text { hygienic } \\
\text { conditions }\end{array}$ & Negative & $\begin{array}{l}\text { Ceftaroline } \\
\text { fosamil, } \\
\text { Meropenem }\end{array}$ & Survived & $\begin{array}{l}\text { Nogi et al., } \\
2016\end{array}$ \\
\hline 10 & 2017 & 41 & $f$ & $\begin{array}{c}\text { Ohio, } \\
\text { United States }\end{array}$ & $\begin{array}{l}\text { Abdominal pain, stage IV right } \\
\text { ischial decubitus ulcer, bilateral } \\
\text { leg lymphedema, congenital } \\
\text { lumbar myelomeningocele } \\
\text { causing paraplegia post spinal } \\
\text { fixation }\end{array}$ & $\begin{array}{l}\text { Poor hygienic } \\
\text { conditions }\end{array}$ & Negative & $\begin{array}{l}\text { Vancomycin, } \\
\text { Cefepime, } \\
\text { Metronidazol }\end{array}$ & Fatal & $\begin{array}{l}\text { Chavez et al., } \\
2017\end{array}$ \\
\hline 11 & 2017 & 47 & $f$ & Malaysia & $\begin{array}{l}\text { Metastatic colorectal } \\
\text { adenocarcinoma, } \\
\text { immunosuppression }\end{array}$ & $\begin{array}{l}\text { Good personal } \\
\text { hygiene }\end{array}$ & Negative & Cefoperazone & Fatal & $\begin{array}{l}\text { Suraiya et al., } \\
\qquad 2017\end{array}$ \\
\hline 12 & 2017 & 79 & $\mathrm{~m}$ & $\begin{array}{l}\text { Dresden, } \\
\text { Germany }\end{array}$ & $\begin{array}{c}\text { Diabetes mellitus, coronary } \\
\text { heart disease, chronic renal } \\
\text { failure, venous } \\
\text { insufficiency/progressive ulceral } \\
\text { disease }\end{array}$ & $\begin{array}{l}\text { Normal social } \\
\text { conditions }\end{array}$ & Negative & $\begin{array}{l}\text { Cefuroxime, } \\
\text { Levofloxacin }\end{array}$ & Survived & $\begin{array}{l}\text { Schröttner } \\
\text { et al., } 2017\end{array}$ \\
\hline 13 & 2017 & 43 & $\mathrm{~m}$ & $\begin{array}{l}\text { Dresden, } \\
\text { Germany }\end{array}$ & $\begin{array}{c}\text { Alcoholism/treatment of alcohol } \\
\text { withdrawal syndrome }\end{array}$ & $\begin{array}{l}\text { Homeless, } \\
\text { alcoholism, } \\
\text { ulceral disease }\end{array}$ & Negative & $\begin{array}{l}\text { No antibiotic } \\
\text { treatment }\end{array}$ & Survived & $\begin{array}{l}\text { Schröttner } \\
\text { et al., } 2017\end{array}$ \\
\hline 14 & 2017 & 78 & $f$ & $\begin{array}{l}\text { Dresden, } \\
\text { Germany }\end{array}$ & $\begin{array}{c}\text { Severe obesity, chronic venous } \\
\text { insufficiency, arterial } \\
\text { hypertension, chronic heart } \\
\text { failure NYHA II/progressive } \\
\text { ulceral disease }\end{array}$ & $\begin{array}{l}\text { Difficult social } \\
\text { conditions }\end{array}$ & Negative & $\begin{array}{l}\text { No antibiotic } \\
\text { treatment }\end{array}$ & Survived & $\begin{array}{l}\text { Schröttner } \\
\text { et al., } 2017\end{array}$ \\
\hline 15 & 2017 & 71 & $\mathrm{~m}$ & $\begin{array}{l}\text { Dresden, } \\
\text { Germany }\end{array}$ & $\begin{array}{c}\text { Deep vein thrombosis, leg } \\
\text { ulcers/speech disorder as } \\
\text { consequence of a tablet and } \\
\text { alcohol intoxication }\end{array}$ & NP & Negative & $\begin{array}{l}\text { No antibiotic } \\
\text { treatment }\end{array}$ & Survived & $\begin{array}{l}\text { Schröttner } \\
\text { et al., } 2017\end{array}$ \\
\hline
\end{tabular}


TABLE 1 | (Continued)

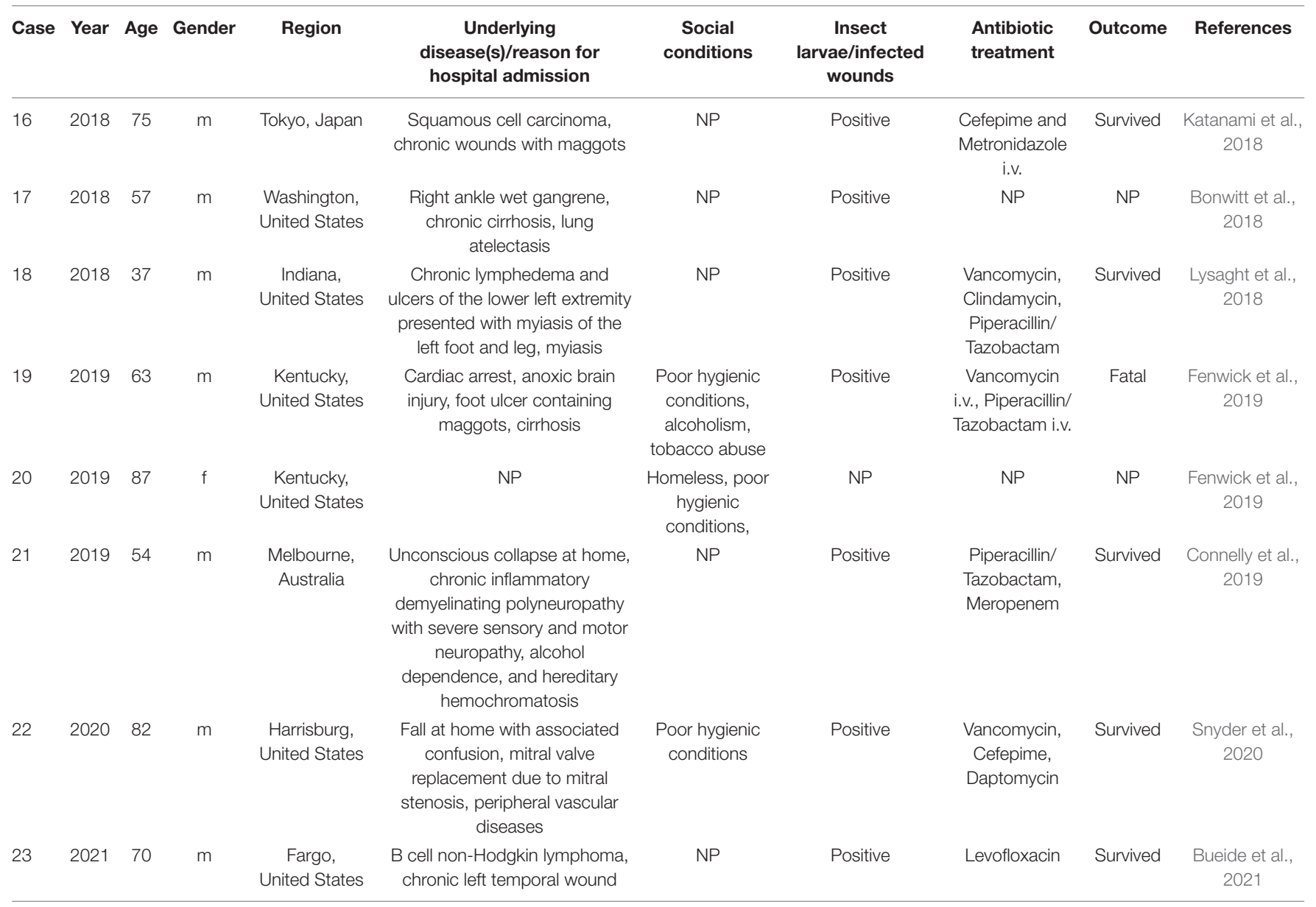

f, female; $m$, male, $N$, not provided.

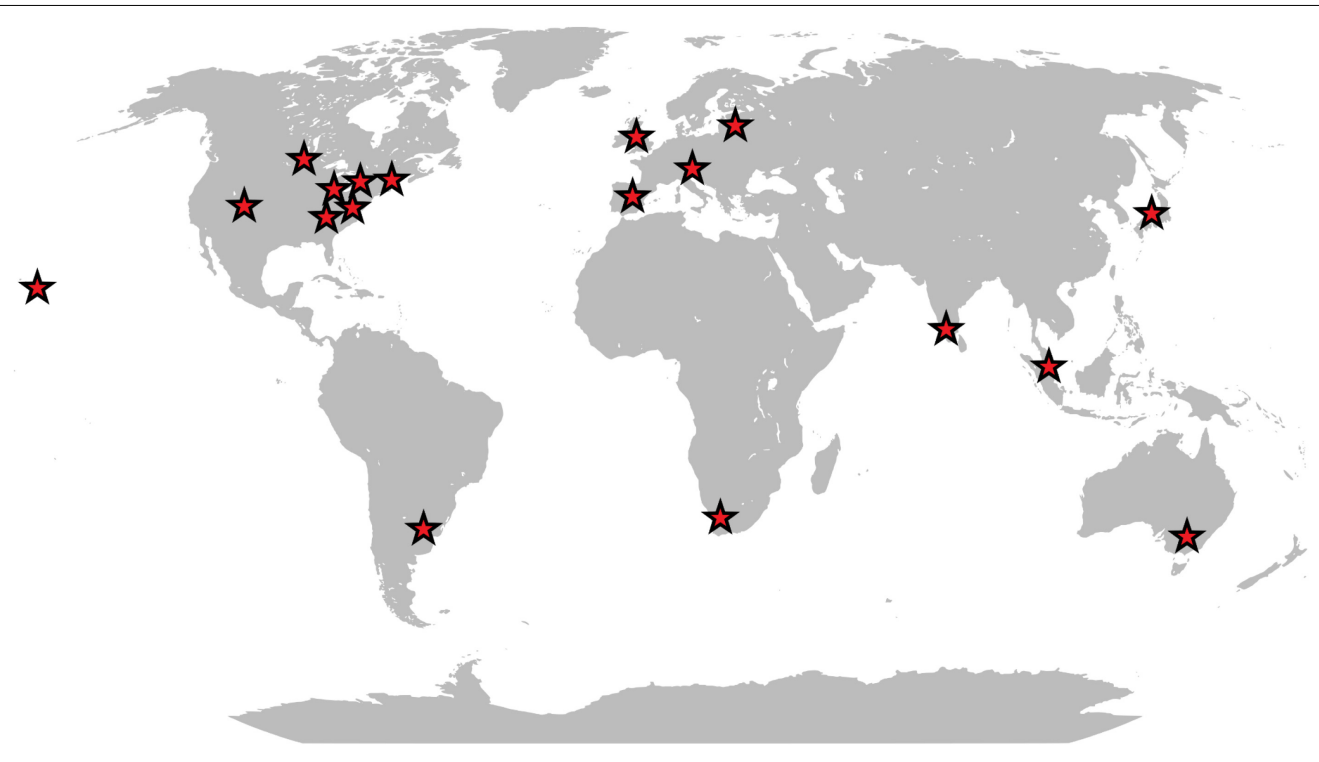

FIGURE 1 | Schematic map showing the geographic distribution of reported human infections caused by $W$. chitiniclastica. 
TABLE 2 | Strain sources and patients' clinical data.

\begin{tabular}{|c|c|c|c|c|c|}
\hline DSM number & Species & Gender & Age & Microbial spectrum & Additional information \\
\hline 100374 & W. chitiniclastica & $\mathrm{m}$ & 43 & Proteus mirabilis & $\begin{array}{l}\text { Homeless, alcoholism, diabetic foot, MRSA screening, } \\
\text { exclusion of tuberculosis }\end{array}$ \\
\hline 100375 & W. chitiniclastica & $\mathrm{m}$ & 78 & Escherichia coli & $\begin{array}{l}\text { Normal social conditions, diabetes mellitus, coronary } \\
\text { heart disease, chronic renal failure, venous } \\
\text { insufficiency/progressive ulceral disease }\end{array}$ \\
\hline 100676 & W. chitiniclastica & $\mathrm{m}$ & 78 & $\begin{array}{l}\text { Staphylococcus aureus, Proteus mirabilis, Serratia } \\
\text { marcescens, Myroides odoratimimus }\end{array}$ & $\begin{array}{l}\text { Difficult social conditions, diabetic foot, ulcus cruris, } \\
\text { severe obesity, chronic venous insufficiency, arterial } \\
\text { hypertension, chronic heart failure NYHA II/progressive } \\
\text { ulceral disease }\end{array}$ \\
\hline 100917 & W. chitiniclastica & $\mathrm{m}$ & 72 & $\begin{array}{l}\text { Proteus mirabilis, Providencia stuartii, Pseudomonas } \\
\text { aeruginosa }\end{array}$ & $\begin{array}{l}\text { Diabetic foot, adiposity, thrombosis, thrombophlebitis, } \\
\text { anticoagulation, speech disorder as consequence of a } \\
\text { tablet, and alcohol intoxication in suicidal intent }\end{array}$ \\
\hline 105708 & W. chitiniclastica & $\mathrm{m}$ & 90 & Morganella morganii, Bacteroides fragilis & Tumorous skin formation (head, neck) \\
\hline 105712 & W. chitiniclastica & $f$ & 82 & $\begin{array}{l}\text { Providencia rettgeri, hemolytic Streptococcus Group G, } \\
\text { Proteus vulgaris }\end{array}$ & Renal failure, ulcus cruris \\
\hline 105838 & W. chitiniclastica & $\mathrm{m}$ & 60 & $\begin{array}{l}\text { Coagulase negative Staphylococcus, Aeromonas } \\
\text { veronii, Klebsiella oxytoca }\end{array}$ & Diabetic foot, MRSA screening \\
\hline 105839 & W. chitiniclastica & $\mathrm{m}$ & 84 & Proteus mirabilis, hemolytic Streptococcus Group C & Diabetic foot, ulcus cruris \\
\hline 105984 & W. chitiniclastica & $\mathrm{m}$ & 60 & $\begin{array}{l}\text { Coagulase negative Staphylococcus, Proteus hauseri, } \\
\text { Klebsiella oxytoca, rod-shaped Corynebacterium spp. }\end{array}$ & Diabetic foot \\
\hline 106597 & W. chitiniclastica & $\mathrm{m}$ & 60 & $\begin{array}{l}\text { Coagulase negative Staphylococcus, } \\
\text { Viridans-Streptococcus, Vagococcus fluvialis, } \\
\text { Morganella morganii, Klebsiella oxytoca }\end{array}$ & Diabetic foot \\
\hline 108048 & W. chitiniclastica & $\mathrm{m}$ & 75 & $\begin{array}{l}\text { Staphylococcus aureus, Proteus penneri/vulgaris, } \\
\text { Providencia rettgeri }\end{array}$ & Type 2 diabetic \\
\hline 108045 & W. chitiniclastica & $\mathrm{m}$ & 65 & Staphlococcus aureus, Proteus vulgaris & Diabetic foot \\
\hline 110179 & W. chitiniclastica & $\mathrm{m}$ & 60 & $\begin{array}{l}\text { Staphylococcus sciuri, coagulase negative } \\
\text { Staphylococcus, Viridans Streptococcus, Klebsiella } \\
\text { oxytoca, Vagococcus fluvialis }\end{array}$ & Diabetic foot \\
\hline 110473 & W. chitiniclastica & $\mathrm{m}$ & 43 & $\begin{array}{l}\text { Proteus mirabilis, Klebsiella oxytoca, Providencia } \\
\text { rettgeri, Staphylococcus aureus }\end{array}$ & NP \\
\hline
\end{tabular}

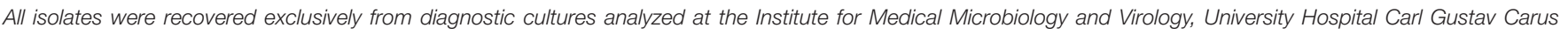
(Dresden, Germany). All strains have been isolated from wound swab.

f, female; $m$, male; NP, not provided.

2016). Oligonucleotides were purchased from Biomers.net (Ulm, Germany). PCR products were purified using exonuclease I and shrimp alkaline phosphatase (both enzymes were purchased from New England Biolabs, Frankfurt am Main, Germany). Sanger sequencing was performed by SEQLAB (Sequence Laboratories Göttingen, Göttingen, Germany). Taxonomic identification was done based on BLASTN (Altschul et al., 1990), using the standard database for Nucleotide collection (nt). Results are displayed in Table 3.

\section{Whole Genome Analysis of W. chitiniclastica}

Libraries for Whole Genome Sequencing (WGS) on the Illumina platform were prepared from extracted genomic DNA, applying the Nextera XT DNA Library Preparation Kit (Illumina, San Diego, United States) with modifications (Baym et al., 2015). Samples were sequenced on the NextSeq ${ }^{\mathrm{TM}} 550$ with a read length $2 \times 150$ bp targeting approx. $100 \times$ genome coverage followed by short read genome assembly using SpaD ES 3.14 (Bankevich et al., 2012). Whole genome sequences were submitted to NCBI GenBank under Acc. Nos JAGIBR000000000-JAGICE000000000, applying the NCBI Prokaryotic Annotation Pipeline PGAP (Tatusova et al., 2016). Contigs smaller than 300 bp were excluded from the submission. For phylogenomic identification and phylogenomic tree construction, genomic contigs were submitted to the Type Strain Genome Server (TYGS) at tygs.dsmz.de, and the type-based species clustering was done using a 70\% dDDH threshold (Meier-Kolthoff and Göker, 2019). Subspecies clustering was based on a $79 \% \mathrm{dDDH}$ threshold as previously introduced (Meier-Kolthoff et al., 2014). Results are displayed in Table 3 and Figure 2.

\section{Antibiotic Profiling}

The antibiotic susceptibility testing of all $W$. chitiniclastica isolates was performed using MIC Test Strips (bestbion, Cologne, Germany) according to the manufacturer's instructions. In brief, a McFarland standard of 0.5 was created for each strain, using $\mathrm{NaCl}$ and a DensiCHEK densitometer (bioMérieux, Nürtingen, Germany). The suspended bacteria were plated with a cotton swab on Müller-Hinton Agar (Oxoid Deutschland, Wesel, Germany). Then, MIC Test Strips (bestbion, Cologne, Germany) for each antibiotic were placed on the agar plates. The plates 
TABLE 3 | Comparison of diagnostic methods applied for identification of W. chitiniclastica.

\begin{tabular}{|c|c|c|c|c|c|}
\hline DSM number & $\begin{array}{c}\text { MALDI-TOF MS } \\
\text { identification results }\end{array}$ & $\begin{array}{c}\text { VITEK } 2 \text { identification } \\
\text { results }\end{array}$ & $\begin{array}{l}\text { 16S rDNA } \\
\text { TPU1_RTU4 }\end{array}$ & 16S rDNA 27F_1492R & dDDH results \\
\hline 100374 & W. chitiniclastica (2.25) & A. Iwoffii (96\%) & $\begin{array}{c}\text { W. chitiniclastica } \\
(99.9 \%)\end{array}$ & $\begin{array}{c}\text { W. chitiniclastica } \\
(99.7 \%)\end{array}$ & $\begin{array}{c}\text { W. chitiniclastica } \\
(74.8 \%)\end{array}$ \\
\hline 100375 & W. chitiniclastica (2.45) & A. Iwoffii (99\%) & $\begin{array}{c}\text { W. chitiniclastica } \\
(99.9 \%)\end{array}$ & $\begin{array}{c}\text { W. chitiniclastica } \\
(99.7 \%)\end{array}$ & $\begin{array}{c}\text { W. chitiniclastica } \\
(74.3 \%)\end{array}$ \\
\hline 100676 & W. chitiniclastica (2.18) & A. Iwoffii (96\%) & $\begin{array}{c}\text { W. chitiniclastica } \\
(99.7 \%)\end{array}$ & $\begin{array}{c}\text { W. chitiniclastica } \\
(99.8 \%)\end{array}$ & $\begin{array}{c}\text { W. chitiniclastica } \\
(74.6 \%)\end{array}$ \\
\hline 100917 & W. chitiniclastica (2.23) & A. Iwoffii (96\%) & $\begin{array}{c}\text { W. chitiniclastica } \\
(99.9 \%)\end{array}$ & $\begin{array}{c}\text { W. chitiniclastica } \\
(99.3 \%)\end{array}$ & $\begin{array}{c}\text { W. chitiniclastica } \\
(74.6 \%)\end{array}$ \\
\hline 105708 & W. chitiniclastica (2.33) & A. Iwoffii (96\%) & $\begin{array}{l}\text { W. chitiniclastica } \\
(100 \%)\end{array}$ & $\begin{array}{c}\text { W. chitiniclastica } \\
(99.4 \%)\end{array}$ & $\begin{array}{c}\text { W. chitiniclastica } \\
(74.1 \%)\end{array}$ \\
\hline 105712 & W. chitiniclastica (2.05) & A. Iwoffii (96\%) & $\begin{array}{c}\text { W. chitiniclastica } \\
(99.9 \%)\end{array}$ & $\begin{array}{c}\text { W. chitiniclastica } \\
(99.6 \%)\end{array}$ & $\begin{array}{c}\text { W. chitiniclastica } \\
(75.0 \%)\end{array}$ \\
\hline 105838 & W. chitiniclastica (2.35) & A. Iwoffii (96\%) & $\begin{array}{c}\text { W. chitiniclastica } \\
(99.2 \%)\end{array}$ & $\begin{array}{c}\text { W. chitiniclastica } \\
(99.7 \%)\end{array}$ & $\begin{array}{c}\text { W. chitiniclastica } \\
(75.1 \%)\end{array}$ \\
\hline 105839 & W. chitiniclastica (2.15) & A. Iwoffii (96\%) & $\begin{array}{c}\text { W. chitiniclastica } \\
(96.9 \%)\end{array}$ & $\begin{array}{c}\text { W. chitiniclastica } \\
(99.7 \%)\end{array}$ & $\begin{array}{c}\text { W. chitiniclastica } \\
(75.0 \%)\end{array}$ \\
\hline 105984 & W. chitiniclastica (2.23) & A. Iwoffii (96\%) & $\begin{array}{c}\text { W. chitiniclastica } \\
(99.6 \%)\end{array}$ & $\begin{array}{c}\text { W. chitiniclastica } \\
(99.7 \%)\end{array}$ & $\begin{array}{c}\text { W. chitiniclastica } \\
(75.0 \%)\end{array}$ \\
\hline 106597 & W. chitiniclastica (2.24) & A. Iwoffii (96\%) & $\begin{array}{c}\text { W. chitiniclastica } \\
(99.9 \%)\end{array}$ & $\begin{array}{c}\text { W. chitiniclastica } \\
(99.8 \%)\end{array}$ & $\begin{array}{c}\text { W. chitiniclastica } \\
(75.0 \%)\end{array}$ \\
\hline 108048 & W. chitiniclastica (2.90) & A. Iwoffii (96\%) & $\begin{array}{c}\text { W. chitiniclastica } \\
(99.9 \%)\end{array}$ & $\begin{array}{c}\text { W. chitiniclastica } \\
(99.3 \%)\end{array}$ & $\begin{array}{c}\text { W. chitiniclastica } \\
(75.1 \%)\end{array}$ \\
\hline 108045 & W. chitiniclastica (2.08) & A. Iwoffii $(96 \%)$ & $\begin{array}{c}\text { W. chitiniclastica } \\
(99.6 \%)\end{array}$ & $\begin{array}{c}\text { W. chitiniclastica } \\
(100 \%)\end{array}$ & $\begin{array}{c}\text { W. chitiniclastica } \\
(74.9 \%)\end{array}$ \\
\hline 110179 & W. chitiniclastica (2.32) & A. Iwoffii (96\%) & $\begin{array}{c}\text { W. chitiniclastica } \\
(99.4 \%)\end{array}$ & $\begin{array}{c}\text { W. chitiniclastica } \\
(99.4 \%)\end{array}$ & $\begin{array}{c}\text { W. chitiniclastica } \\
(75.0 \%)\end{array}$ \\
\hline 110473 & W. chitiniclastica (2.32) & A. Iwoffii (92\%) & $\begin{array}{c}\text { W. chitiniclastica } \\
(99.7 \%)\end{array}$ & $\begin{array}{c}\text { W. chitiniclastica } \\
(99.1 \%)\end{array}$ & $\begin{array}{c}\text { W. chitiniclastica } \\
(74.0 \%)\end{array}$ \\
\hline $18708^{\top *}$ & W. chitiniclastica (2.26) & A. Iwoffii (96\%) & $\begin{array}{c}\text { W. chitiniclastica } \\
(99.9 \%)\end{array}$ & $\begin{array}{c}\text { W. chitiniclastica } \\
(99.4 \%)\end{array}$ & $\begin{array}{c}\text { W. chitiniclastica } \\
(100 \%)\end{array}$ \\
\hline
\end{tabular}

The type strain DSM $18708^{T}$ was included as reference.

$T *$ Type strain as reference.

were incubated for $18 \pm 2 \mathrm{~h}$ at $37^{\circ} \mathrm{C}$. The $\mathrm{MIC}$ results were evaluated by applying the guidelines for PK/PD (non-speciesrelated) breakpoints according to the criteria published by EUCAST (European Committee on Antimicrobial Susceptibility Testing), using Version 11.0, 01. January 2021. ${ }^{2}$ Results are displayed in Table 4. For the type strain DSM $18708^{\mathrm{T}}$, results are represented in Supplementary Table 6. All MIC Test Strips used in this study and their MIC ranges are listed in Supplementary Table 2 . The comprehensive antibiotic resistance database $\mathrm{CARD}^{3}$ was used for in silico prediction of antibiotic resistance genes (Alcock et al., 2020). Results are listed in Supplementary Tables 3, 4 .

\section{RESULTS}

\section{Strain Collection and Its Characteristics}

An overview of the W. chitiniclastica strain collection analyzed in this study is given in Table 2. All isolates were collected

${ }^{2}$ http://www.eucast.org/clinical_breakpoints/

${ }^{3}$ https://card.mcmaster.ca/ from wound swabs and patients' medium age was 67.86 years ranging from 43 to 90 years. The majority were male $(n=13)$ and suffered from diabetes. There was only one female patient. This patient suffered from renal failure. Information regarding the social situation and living conditions were provided only in three cases (Schröttner et al., 2017). One patient (case 2) was homeless while one (case 3) lived under poor hygienic conditions. In contrast to these two, one patient (case 1) lived under normal conditions, which were not further specified. The associated microbial spectrum consists of Staphylococcus spp., Pseudomonas spp., Proteus spp., and Streptococcus spp. among others. Therefore, it remains unclear if $W$. chitiniclastica was the causative agent of the diseases or part of the microbiome.

\section{Identification of W. chitiniclastica Based on 16S rRNA Gene Analysis}

16S rRNA amplification from pure culture of each isolate was successful and both primer pairs have proven of value (Table 2). In all cases sequence identity for W. chitiniclastica was above $\geq 98.7 \%$ and therefore fulfilling the criteria for bacterial species identification (Meier-Kolthoff et al., 2013b). 


\section{Identification of W. chitiniclastica Based on MALDI-TOF MS}

Wohlfahrtiimonas chitiniclastica was successfully identified by MALDI-TOF MS (Schröttner et al., 2016). Based on the manufacturer's guidelines, score values above 2.0 are interpreted as secure identification at both the genus and species levels; scores between 2.0 and 1.7 as reliable identification on the genus, but not at the species level; and scores below 1.7 were regarded as an unreliable identification (Schröttner et al., 2016). In this study, all scores were above 2 (Table 2), allowing us to identify all isolates as $W$. chitiniclastica with high confidence.

\section{Results Obtained for Identification of W. chitiniclastica From VITEK 2}

VITEK 2 results of $W$. chitiniclastica lead to misidentification as Acinetobacter lwoffii of all strains included in this study (Table 3), which has also been reported in previous case reports (de Dios et al., 2015; Chavez et al., 2017; Snyder et al., 2020). Identification of DSM 110473 resulted in 92\% probability for species identification. Based on the manufacturer's instructions 89-92\% probability correlates with a good confidence level. Notably, for the remaining isolates, the results were above $96 \%$, representing an excellent species identification; however, in our study a misidentification as $A$. Iwoffii was evident for all strains.
Biochemical characteristics based on the VITEK 2 system showed positive results for tyrosine arylamidase, Ellman's reagent, L-lactate alkalization, and oxidase (Supplementary Table 5).

\section{Identification of W. chitiniclastica Based on Whole Genome Sequencing}

Phylogenomic analysis of all 14 strains revealed correct taxonomic assignment to $W$. chitiniclastica. Hereby, dDDH values of $74.0-75.1 \%$ (Table 3 ) were computed against the type strain of the species DSM $18708^{\mathrm{T}}$ and therefore fulfilling the criteria for bacterial species identification (Meier-Kolthoff and Göker, 2019). A phylogenomic tree based on wholegenome sequences was constructed using the TYGS web server $^{4}$ (Figure 2) and all 14 isolates cluster in one subclade with the type strain DSM $18708^{\mathrm{T}}$. Notably, the isolates from Dresden form a new subspecies using a $79 \% \mathrm{dDDH}$ threshold (Meier-Kolthoff et al., 2014).

\section{Antibiotic Profiling}

The susceptibility profile and the MIC distribution of all strains tested using MIC Test Strips are summarized in Table 4. Additionally, the MIC results of each isolate are provided in Supplementary Table 1 . All 14 strains were susceptible to all

${ }^{4}$ https://tygs.dsmz.de/

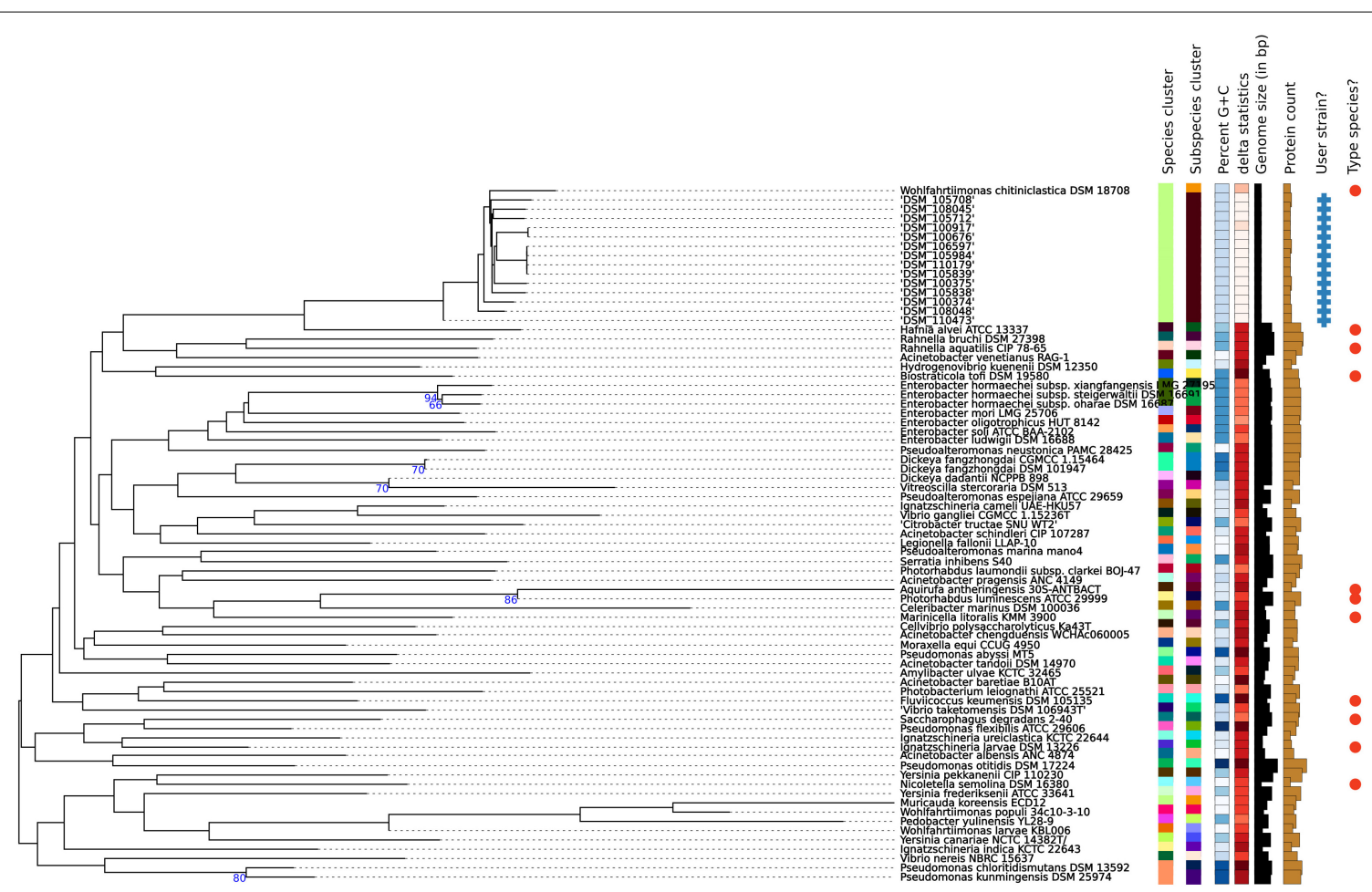

FIGURE 2 | Phylogenomic tree of the W. chitiniclastica species and subspecies delineation based on the GBDP phylogenetic analyses retrieved from the TYGS website. The tree was inferred with FastME 2.1.6.1 (Lefort et al., 2015) from GBDP distances calculated from genome sequences and was subjected to a clustering using established thresholds for delineating species (DDH > 70\%) (Meier-Kolthoff et al., 2013a) as well as subspecies (DDH > 79\%) (Meier-Kolthoff et al., 2014). The branch lengths are scaled in terms of GBDP distance formula d5. The numbers above branches are GBDP pseudo-bootstrap support values $>60 \%$ from 100 replications, with an average branch support of $83.0 \%$. 
penicillins, carbapenems, cephalosporines, and monobactams tested in this study. This is in line with the susceptibility profile of the type strain DSM $18708^{\mathrm{T}}$ (Supplementary Table 5).

In addition, all 14 strains were susceptible to the fluoroquinolones tested in this study, apart from two exceptions. The isolates DSM 105984 and DSM 106597 were resistant to ofloxacin and moxifloxacin (Supplementary Table 1). Interestingly, these two strains showed higher MIC values for all tested fluoroquinolones in comparison to the other strains (Supplementary Table 1). A similar picture was obtained for the tetracycline tigecycline. The majority were susceptible while DSM 105984 and DSM 106597 appear to be resistant. In contrast, all strains appear to be resistant to the aminoglycosides amikacin and tobramycin. In addition, 10 strains showed resistance to gentamicin. The type strain DSM $18708^{\mathrm{T}}$ appears to be susceptible to all three aminoglycosides tested in this study (Supplementary Table 5).

No breakpoints were available for trimethoprim/sulfamethoxazole, fosfomycin, doxycycline, colistin, chloramphenicol, nitrofurantoin, rifampicin, and macrolides. However, the MIC results determined for fosfomycin are all at a high range. Therefore, antimicrobial resistance to this antibiotic may be assumed. On the contrary, low MIC results were obtained for trimethoprim/sulfamethoxazole making susceptibility feasible.

The Comprehensive Antibiotic Resistance Database (CARD) (Alcock et al., 2020) was used for in silico identification of potential genes encoding for antibiotic resistance. Using the parameters "Perfect hit and Strict hit only" and "Highquality/coverage," the strains DSM 100676, DSM 100917, and DSM 105708 each revealed one strict hit for tet(D) with an identity of $52.28 \%$ for the matching region (Supplementary Table 3). The "Strict" algorithm of the CARD system represents a flexible sequence variation but lies within the curated BLAST bit score cut-offs (Alcock et al., 2020) and by that making a correct identification still highly feasible. For the remaining isolates, no perfect or strict hits were obtained. However, when the parameter was changed to "Perfect hit, Strict hit, and Loose hit," about 150 hits per strain were revealed with an identity for the matching region from 21 to $81 \%$. Detailed results are displayed in Supplementary Table 3. However, keeping in mind that the "Loose" algorithm of the CARD system works outside of the detection model cut-offs to provide detection of new and more distant homologs of antimicrobial resistance (AMR) genes (Alcock et al., 2020), in silico results based on loose hits should always be taken with caution and require further research. Nevertheless, it could help us to identify potential resistance genes and/or shed light on new unknown modifications.

With respect to the resistance mechanism, the majority of hits belonged to antibiotic target alteration and efflux systems (Supplementary Table 4). Attention should be paid to genes mentioned as follows: Up to six genes encoding for fosfomycin efflux proteins were identified, and each strain showed a hit for MurA transferase with mutation conferring resistance to fosfomycin, which is involved in antibiotic target alteration of fosfomycin (Fu et al., 2015). In addition, several genes involved in broad range efflux systems of diverse antibiotics such as aminoglycosides, makrolides, fluoroquinolones, and tetracycline were detected including genes coding for macrolide-specific efflux pumps (macA and macB) (Kobayashi et al., 2000; Yum et al., 2009). Each strain also contained genes encoding for aminoglycoside resistant mechanisms such as apmA, baeS, and cpxA. Interestingly, all isolates revealed hits for the trimethoprim resistance gene $d f r I(56.63 \%$ identity) and the sulfonamide resistance gene sul3 (39.85\% identity), as well as several hits for potential genes coding for $\beta$-lactamases, such as PNGM-1, NmcR, and GOB-16, although identity of the matching region was less than $36 \%$ in all cases.

\section{DISCUSSION}

The majority of the W. chitiniclastica isolates collected for the study was associated with chronic open skin wounds and related to comorbidities, such as diabetes. Moreover, poor social and hygienic conditions can be considered a risk factor for an infection with this human pathogen (Schröttner et al., 2017). These findings are in line with previous case studies, which further emphasize the correlation between the emergence of infectious diseases and social and economic inequalities (Campisi et al., 2015; de Dios et al., 2015; Suryalatha et al., 2015; Nogi et al., 2016; Chavez et al., 2017). Other microbial species were detected along with $W$. chitiniclastica, making it difficult to modulate the pathogenic potential of one or the other and/or appoint the causative agent of the infection in our collection. Although only rudimentary information is available and no thorough characterization of the microbial community took place, it is interesting to note that similarities to the diabetic foot microbiome occur. The genera Staphylococcus, Pseudomonas as well as Streptococcus were recently described as dominant taxa in chronic diabetic foot ulcers (Gardner et al., 2013; Wolcott et al., 2016; Gardiner et al., 2017) while Proteus spp. was specific to individuals (Gardiner et al., 2017). Although W. chitiniclastica occurred as part of polymicrobial infections (Campisi et al., 2015; de Dios et al., 2015; Kõljalg et al., 2015; Nogi et al., 2016), it has not yet been reported to be an abundant member of the diabetic skin and/or wound microbiome. However, further research could uncover its specific role and potential pathogenicity in association with chronic wounds and diseases, such as diabetes.

16S rRNA sequencing has proven to be a good and rapid identification method for bacterial organisms directly from clinical samples. However, the diagnostic power of this technique heavily depends on the choice of primer (Armougom, 2009; Klindworth et al., 2012) as well as the amplicon length and coverage of variable regions (Sune et al., 2020). Suboptimal primers can fail to detect single species or even whole groups (Andersson et al., 2008; Tringe and Hugenholtz, 2008; Wang and Qian, 2009), and the different variable regions within the $16 \mathrm{~S}$ rRNA gene exhibit varying degrees of sequence diversity while no single region is able to distinguish among all bacteria (Chakravorty et al., 2007). Therefore, careful choice of primer pairing prior to amplification is strongly recommended. In this study, we decided to choose primer pairs, which are 
TABLE 4 | Minimum inhibitory concentration (MIC) distribution of 14 W. chitiniclastica strains.

resistant strains in\%

\begin{tabular}{|c|c|c|c|c|c|c|c|c|c|c|c|c|c|c|c|c|c|c|c|c|c|c|c|}
\hline Antibiotic & $<0.002$ & 0.002 & 0.004 & 0.008 & 0.016 & 0.032 & 0.064 & 0.125 & 0.25 & 0.5 & 1 & 2 & 4 & 8 & 16 & 32 & 64 & 128 & 256 & 512 & s & I & $\mathbf{R}$ \\
\hline Amikacin & & & & & & & & & & & & & & & & & & & & & $0 \%$ & $0 \%$ & $100 \%$ \\
\hline Gentamicin & & & & & & & & & & 1 & 3 & & & & & & & & & & $29 \%$ & $0 \%$ & $71 \%$ \\
\hline Tobramycin & & & & & & & & & & & & & & & & & & & & & $0 \%$ & $0 \%$ & $100 \%$ \\
\hline Doripenem & & & & & & 2 & 10 & 2 & & & & & & & & & & & & & $100 \%$ & $0 \%$ & $0 \%$ \\
\hline Ertapenem & 1 & & 1 & 8 & 4 & & & & & & & & & & & & & & & & $100 \%$ & $0 \%$ & $0 \%$ \\
\hline Imipenem & & & & & & & & & 7 & 7 & & & & & & & & & & & $100 \%$ & $0 \%$ & $0 \%$ \\
\hline Meropenem & & & 1 & 4 & 7 & 2 & & & & & & & & & & & & & & & $100 \%$ & $0 \%$ & $0 \%$ \\
\hline Cefepime & 6 & & & 5 & 3 & & & & & & & & & & & & & & & & $100 \%$ & $0 \%$ & $0 \%$ \\
\hline Ceftazidime & & & & & & 2 & 7 & 5 & & & & & & & & & & & & & $100 \%$ & $0 \%$ & $0 \%$ \\
\hline Cefuroxime & & & & & & 3 & 3 & 6 & 1 & 1 & & & & & & & & & & & $100 \%$ & $0 \%$ & $0 \%$ \\
\hline Ciprofloxacin & & & & & 2 & 2 & 8 & 1 & 1 & & & & & & & & & & & & $100 \%$ & $0 \%$ & $0 \%$ \\
\hline Levofloxacin & & & & & & 2 & 7 & 3 & & 2 & & & & & & & & & & & $100 \%$ & $0 \%$ & $0 \%$ \\
\hline Moxifloxacin & & & & & & & 3 & 5 & 4 & 1 & 1 & & & & & & & & & & $86 \%$ & $0 \%$ & $14 \%$ \\
\hline Ofloxacin & & & & & & & 1 & 5 & 6 & & 2 & & & & & & & & & & $86 \%$ & $0 \%$ & $14 \%$ \\
\hline Azithromycin & & & & & & & & & 1 & 6 & 3 & 1 & & 3 & & & & & & & $\mathrm{IE}$ & $\mathrm{IE}$ & $\mathrm{IE}$ \\
\hline Clarithromycin & & & & & & & & & & & & 8 & 1 & 3 & 2 & & & & & & $\mathrm{IE}$ & $\mathrm{IE}$ & $\mathrm{IE}$ \\
\hline Erythromycin & & & & & & & & & & & & 2 & 9 & 1 & 1 & 1 & & & & & $\mathrm{IE}$ & $\mathrm{IE}$ & $\mathrm{IE}$ \\
\hline Aztreonam & 14 & & & & & & & & & & & & & & & & & & & & $100 \%$ & $0 \%$ & $0 \%$ \\
\hline Amoxicillin/Clavulanic acid & & & & & & & 1 & 1 & 9 & 3 & & & & & & & & & & & $100 \%$ & $0 \%$ & $0 \%$ \\
\hline Ampicillin & & & & & & & 3 & 1 & 8 & 2 & & & & & & & & & & & $100 \%$ & $0 \%$ & $0 \%$ \\
\hline Ampicillin/Sulbactam & & & & & & & 1 & 5 & 7 & 1 & & & & & & & & & & & $100 \%$ & $0 \%$ & $0 \%$ \\
\hline Piperacillin & & & & & & & 1 & 2 & 4 & 3 & 2 & 2 & & & & & & & & & $100 \%$ & $0 \%$ & $0 \%$ \\
\hline Piperacillin/Tazobactam & & & & & & & & & 3 & 6 & 2 & 3 & & & & & & & & & $100 \%$ & $0 \%$ & $0 \%$ \\
\hline Doxycycline & & & & & & & & & 3 & 5 & 1 & 2 & 2 & 1 & & & & & & & $\mathrm{IE}$ & $\mathrm{IE}$ & $\mathrm{IE}$ \\
\hline Tigecycline & & & & & & & & & 7 & 5 & & 2 & & & & & & & & & $100 \%$ & $0 \%$ & $14 \%$ \\
\hline Chloramphenicol & & & & & & & & & & & 1 & 11 & & 1 & 1 & & & & & & $\mathrm{IE}$ & $\mathrm{IE}$ & $\mathrm{IE}$ \\
\hline Colistin & & & & & & & & & & & 2 & 12 & & & & & & & & & $\mathrm{IE}$ & $\mathrm{IE}$ & $\mathrm{IE}$ \\
\hline Fosfomycin & & & & & & & & & & & & & & & & & & 9 & 2 & 3 & $\mathrm{IE}$ & $\mathrm{IE}$ & $\mathrm{IE}$ \\
\hline Nitrofurantoin & & & & & & & & & & & & 6 & 8 & & & & & & & & $\mathrm{IE}$ & $\mathrm{IE}$ & $\mathrm{IE}$ \\
\hline Rifampicin & & & & & & & & & 4 & 8 & 2 & & & & & & & & & & $\mathrm{IE}$ & $\mathrm{IE}$ & $\mathrm{IE}$ \\
\hline Trimethoprim/Sulfamethoxazole & & & & & & & 5 & 9 & & & & & & & & & & & & & $\mathrm{IE}$ & $\mathrm{IE}$ & $\mathrm{IE}$ \\
\hline
\end{tabular}

This table summarizes the resistance profiles determined for $14 \mathrm{~W}$. chitiniclastica strains. The MIC results are given in $\mu \mathrm{g} / \mathrm{ml}$. The number of isolates tested for each antibiotic is summarized in this table. Susceptible isolates are highlighted in green color, intermediate in yellow and resistant isolates in red. Blue color is used to illustrate the cases with insufficlEnt evidence (IE) that the antibiotic can successfully be administered to the patIEnt. In these instances, breakpoints are not provided by the EUCAST. Additionally, the percentages of susceptible and resistant strains are given. 
well-established in clinical routine diagnostics and satisfy with a good in silico coverage for the genus Wohlfahrtiimonas. Assuming that a standard PCR can tolerate up to two mismatches between the primer and its target (Nossa et al., 2010), the two primer pairs were chosen based on their TestPrime results (Klindworth et al., 2012) with an in silico coverage of $100 \%$, and we are pleased to report that both primer pairs successfully amplified the $16 \mathrm{~S}$ gene sequence of $W$. chitiniclastica from pure culture.

TPU-1/RTU-4 has been widely used in medical research as well as routine diagnostics (Funke et al., 2004; Haanperä et al., 2007; Broecker et al., 2016; Rudolph et al., 2019) and generates a shorter $\sim 800$ bp fragment spanning hypervariable region V1 through V5, respectively. Hereby, V1-V3 is expected to provide reasonable taxonomic resolution to discriminate between taxa (Johnson et al., 2019) and enabled us to identify each isolate as $W$. chitiniclastica. However, it has been shown that taxonomic analysis based on short amplicons cannot achieve the taxonomic resolution afforded by sequencing the entire $(\sim 1,500 \mathrm{bp})$ gene (Johnson et al., 2019), which still poses a problem for indepth phylogenetic analysis (Tringe and Hugenholtz, 2008; Nossa et al., 2010; Johnson et al., 2019). The combination 27F/1492R overcomes this limitation by generating amplicons, spanning all nine hypervariable regions, which we would recommend when accurate classification of individual organisms at very high taxonomic resolution is required. In summary, TPU-1/RTU-4 as well as $27 \mathrm{~F} / 1492 \mathrm{R}$ is suitable for amplification of the $16 \mathrm{~S}$ rRNA gene of $W$. chitiniclastica from pure culture and leads to correct identification. Although this has not been tested yet, we believe that both primer pairs are also suitable to detect $W$. chitiniclastica within the scope of a thorough microbial community profiling.

MALDI-TOF MS-based microbial identification is a wellestablished method in routine diagnostics (Mellmann et al., 2008; Schröttner et al., 2016). Although limitation on species level identification due to missing spectra in the database of unknown species might occur (Timperio et al., 2017; Strejcek et al., 2018), it has the advantage of speed and low cost, which most likely have priority in daily clinical practice (Seng et al., 2009). In case of an infection with $W$. chitiniclastica it excels as a fast and inexpensive identification tool.

The VITEK 2 system proved to be ineffective for identification of $W$. chitiniclastica isolates as previously reported (de Dios et al., 2015; Chavez et al., 2017; Snyder et al., 2020). The information about this bacterium appears to be missing the VITEK 2 database, leading to misidentification as A. Iwoffii. Both organisms are Gram-negative, rod-shaped and show almost identical biochemical characteristics. Based on the VITEK 2 system, differences occur only with respect to the oxidase reaction. A. Iwoffii is oxidase negative unlike $W$. chitiniclastica (Tóth et al., 2008; de Dios et al., 2015). Little is known about a potential natural habitat of $W$. chitiniclastica in humans apart from its association to parasitic flies, unlike $A$. lwoffi, which is described to be part of the physiological skin flora (Seifert et al., 1997; Berlau et al., 1999) but could also cause severe infections in humans ( $\mathrm{Ku}$ et al., 2000). The latter could be problematic since Acinetobacter species are known for inherent resistance against many of the available antimicrobial agents (Tripathi et al., 2014), leading for example to multidrugresistant clinical isolates of $A$. lwoffii (Hu et al., 2011). Although most Acinetobacter strains are still susceptible to carbapenems (Peleg et al., 2008), first resistances have emerged (Eliopoulos et al., 2008), making it a significant challenge to treat possible infections. W. chitiniclastica, on the other hand, appears to be susceptible to the majority of known antibiotics (Schröttner et al., 2017; Matos et al., 2019). Due to this contrary picture in terms of susceptibility for these two organisms, appropriate identification of the causing microorganisms and their resistance profiles is crucial to limit formation of multidrug-resistant species. With the currently available database, the VITEK 2 system appears not to be reliable and we therefore do not advocate for this method. For the identification of $W$. chitiniclastica isolates, we would rather recommend using MALDI-TOF MS and 16S rRNA gene sequencing. Although both serve as reliable identification tools, we would endorse a combination of both methods as it leads to a higher reliability and more robust identification accuracy (Schröttner et al., 2016), which is especially beneficial in case of doubtful results (Schröttner et al., 2014). Keeping in mind that neither MALDI-TOF MS nor 16S rRNA gene sequencing might be in use for routine diagnostics in every diagnostic laboratory, $W$. chitiniclastica might be even more common but misidentified due to a suboptimal diagnostic method. Moreover, with 23 human case reports from 18 different locations a clear geographical clustering appears to be missing (Table $\mathbf{1}$ and Figure 1) suggesting a potential spread and transmission. This further emphasize the hypothesis that $W$. chitiniclastica might be not as rare as originally anticipated.

Our study indicates that $\mathrm{dDDH}$ has proven a worthy identification method for $W$. chitiniclastica; however, since $\mathrm{dDDH}$ is a very costly and time-consuming technique and requires access to next generation sequencing technology (NGS), it is most likely irrelevant in daily clinical routine diagnostics. Notably, our 14 isolates from Dresden cluster in a subspecies, a fact that has not been described for any $W$. chitiniclastica strain yet. Subspecies are known to show adaptation to different environments (Biller et al., 2015; Lamas et al., 2018) and geographical locations (Truong et al., 2015; Costea et al., 2017). For example, recent studies of the human gut showed that discrete subspecies of the species Agathobacter rectalis and Prevotella copri are associated with geographically distinct human populations (Truong et al., 2015; Costea et al., 2017), whereas few strains occurred in multiple unrelated cohorts (Truong et al., 2015). Keeping in mind that the type strain DSM $18708^{\mathrm{T}}$ has been isolated from animal source in Hungary (Tóth et al., 2008), the formation of a novel subspecies within the 14 isolates from Dresden most likely represents the adaptation to a human environment or a different geographic location. With hopefully increasing numbers of available genomes associated to human cases preferentially from various locations, large-scale genome analysis is recommended to unravel phenotypic and/or genotypic differences within the W. chitiniclastica clade. 
Wohlfahrtiimonas chitiniclastica are described to be susceptible to the majority of known antibiotics with the exception of fosfomycin (Schröttner et al., 2017; Matos et al., 2019); however, no comprehensive and comparative antimicrobial resistance profiling of a larger strain collection has been performed so far. Based on our in vitro susceptibility testing, all $W$. chitiniclastica isolates appear to be susceptible to $\beta$-lactam antibiotics such as penicillins, cephalosporines, monobactams, and carbapenems. This is in contrast to the complete genome sequence analysis of the $W$. chitiniclastica strain BM-Y, which carried a $b l a_{V E B-1}$ gene cassette, thus conferring resistance to ceftazidime and ampicillin, among others (Zhou et al., 2016). Interesting to note is that our in silico analysis also revealed potential genes coding for $\beta$-lactamases such as PNGM-1 (Park et al., 2018), NmcR (Naas and Nordmann, 1994) and GOB-16 (Morán-Barrio et al., 2007); however, the identity of the matching region was less than $36 \%$ in all cases. Therefore, we believe that $W$. chitiniclastica contains at most an incomplete beta-lactamase or a homologous protein with a yet unknown function. This is in line with previous case studies, where cephalosporins, such as cefuroxime, have proven to be successful to treat infections caused by $W$. chitiniclastica (Rebaudet et al., 2009; Campisi et al., 2015; Suryalatha et al., 2015; Snyder et al., 2020; Bueide et al., 2021), and by that supporting our results of a comprehensive susceptibility against a wide majority of $\beta$-lactam antibiotics.

All 14 strains were susceptible to the fluoroquinolones ciprofloxacin and levofloxacin. This is congruent with two case studies, where an infection caused by $W$. chitiniclastica was successfully treated with levofloxacin (Schröttner et al., 2017; Bueide et al., 2021) as well as brief antibiotic susceptibility tests within individual clinical reports (de Dios et al., 2015; Kõljalg et al., 2015; Chavez et al., 2017; Katanami et al., 2018; Snyder et al., 2020). In this study, the majority of the isolates was also susceptible to moxifloxacin and ofloxacin apart from two exceptions. The isolates, DSM 105984 and DSM 106597, appear to be resistant. Interestingly, based on our in silico analysis, all isolates contained a point mutation in $\operatorname{gyrB}$ (58.73\% identity), known to confer resistance to moxifloxacin in Clostridioides difficile (Walkty et al., 2010). However, a previous study showed that not all mutations leading to amino acid substitution in GyrB seem to be relevant, as at least one was also detected in susceptible strains (Spigaglia et al., 2008). Further research will be necessary to gain a better understanding whether this point mutation plays any role in resistance or not. Our in silico results could serve as basis for identifying potential target genes for a thorough sequence analysis and/or genetic mutations. Until then, ciprofloxacin and levofloxacin may be the best fluoroquinolones to use.

In vitro analysis with respect to tetracycline resistances showed a rather diverse picture. We obtained diversified MIC results for doxycycline, ranging from 0.35 up to $8 \mu \mathrm{g} / \mathrm{ml}$. Unfortunately, no EUCAST guideline is available, and to the best of our knowledge, no case reports have been published so far. In the case of tigecycline, 12 isolates were susceptible while DSM 105984 and DSM 106597 were resistant. This rather diverse resistance profile for tetracycline is also reflected in the literature. In some case studies, the isolate was susceptible to tetracyclines (Almuzara et al., 2011; Nogi et al., 2016), and in another report, it was resistant (Snyder et al., 2020). This rather varying picture continues within the present in silico study. Resistance to tetracyclines can be governed by tet genes, such as tet $(D)$, which encode for a tetracycline antibiotic efflux pump (Levy et al., 1999; Hedayatianfard et al., 2014). Interestingly, the strains DSM 100676, DSM 100917, and DSM 105708 revealed one strict hit each for tet(D) with an identity of $52.28 \%$ for the matching region. Unfortunately, this is not congruent with the in vitro results for tigecycline, in which the strains DSM 100676, DSM 100917, and DSM 105708 were susceptible. Interestingly, for doxycycline, these three strains showed comparatively high MIC values with 4 and $8 \mu \mathrm{g} / \mathrm{ml}$, respectively (Supplementary Table 1). Keeping in mind that the "Strict" algorithm of the CARD system represents a flexible sequence variation but lies within the curated BLAST bit score cut-offs (Alcock et al., 2020), resistance to doxycycline governed by tet(D) among others therefore appears to be feasible. The two tigecycline resistant isolates, DSM 106584 and DSM 106597, on the other hand, had no hits to tet(D) but loose hits to several efflux pumps and to a gene encoding for the mobile Tet(X) ortholog, which is described to confer high-level tigecycline resistance (Fang et al., 2020). However, since we only found loose hits, these in silico results should be taken with caution and require further research. This leaves us with a rather questionable picture regarding the tetracycline resistance profile, which still needs to be resolved.

Aminoglycosides (AG), such as amikacin, gentamicin, and tobramycin, are broad-spectrum antibiotics and interfere with the bacterial protein translation by binding to the bacterial ribosome. Common AG resistance mechanism include modification of the AG binding site by $16 \mathrm{~S}$ rRNA methyltransferases (RMTases) and antibiotic target alteration by aminoglycoside phosphotransferases (APHs), aminoglycoside nucleotidyltransferases (ANTs), and aminoglycoside acetyltransferases (AACs) (Yokoyama et al., 2003; Fessler et al., 2011). Based on our in silico analysis, all strains contain a homolog to the apmA gene encoding for an AAC with 47.92\% identity for the matching region. In addition, several hits for efflux pumps specific for aminoglycoside and aminocoumarin, such as baeS (Baranova and Nikaido, 2002; Nishino et al., 2005) and cpxA (Srinivasan et al., 2012), were identified, but the result should be viewed with caution since only loose hits are present and the percentage of the matching region was comparatively low, with 27.93 and $33.45 \%$, respectively. Nevertheless, the in vitro experiments support the in silico analysis, which showed that all strains were resistant to amikacin and tobramycin. Similar results were obtained for the type strain DSM $18708^{\mathrm{T}}$ (Supplementary Table 5), suggesting a natural aminoglycoside resistance profile. Moreover, other case studies detected analogous MIC results for amikacin and tobramycin (Kõljalg et al., 2015; Chavez et al., 2017; Katanami et al., 2018), but the interpretation of antibiotic susceptibility was based on the MIC breakpoints for other 
non-Enterobacteriaceae described in the M100 Performance Standards for Antimicrobial Susceptibility Testing, determined by the Clinical and Laboratory Standards Institute (CLSI) (Wayne and Clinical and Laboratory Standards Institute (CLSI), 2016). Therefore, those isolates were described as susceptible. Although previous studies showed an acceptable level of comparability between EUCAST and CLSI (Kassim et al., 2016; Akdoğan et al., 2021), one should always keep in mind that even small differences might influence the therapeutic option. We rather consider $W$. chitiniclastica as resistant to amikacin and tobramycin and would therefore not recommend aminoglycosides as first line treatment. However, reevaluation is strongly recommended when updated EUCAST breakpoints become available.

No EUCAST guidelines exist for trimethoprim/sulfamethoxazole, rifampicin, nitrofurantoin, fosfomycin, colistin, doxycyclin, erythromycin, azithromycin, and clarithromycin. However, for some antimicrobial substances, the in vitro analysis revealed comparatively low or high MIC values, respectively. This allows us to generate a hypothesis regarding the resistance profile for some isolates. For instance, we observed comparatively low MIC values for trimethoprim/sulfamethoxazole. This is in line with recent case reports, in which $W$. chitiniclastica were susceptible to trimethoprim/sulfamethoxazole (Chavez et al., 2017; Katanami et al., 2018; Connelly et al., 2019; Snyder et al., 2020; Bueide et al., 2021). Interestingly, all isolates revealed in silico hits for the trimethoprim resistant gene $d f r I$ (Welch et al., 2007) $(56.63 \%$ identity) and the sulfonamide resistance gene sul3 (Perreten and Boerlin, 2003) (39.85\% identity), assuming that resistance may be feasible. However, previous studies of Escherichia coli reported that trimethoprim resistant genes were not expressed due to defective promotors (Mazurek et al., 2015). Therefore, we believe that susceptibility toward trimethoprim/sulfamethoxazole of all isolates tested in this study appears to be feasible, despite the presence of potential resistance genes. Nevertheless, antimicrobial resistome analysis prior to treatment is always recommended as newly emerged resistance might arise quickly. For example, the first reported case of $W$. chitiniclastica infection in South Africa surprised with trimethoprim/sulfamethoxazole resistance (Hoffmann et al., 2016). To the best of our knowledge, this is the first report in which an isolate appears to be resistant.

Moderate MIC values for clarithromycin and erythromycin in combination with in silico detection of homologs genes coding for macrolide-specific efflux pumps ( $m a c A$ and macB) (Kobayashi et al., 2000; Yum et al., 2009) make resistance feasible. This is congruent with a preliminary genome report of a $W$. chitiniclastica strain, which also contained $m a c A$ and $m a c B$ genes (Matos et al., 2019). Nevertheless, further research is still required to uncover the macrolide resistance profile fully.

Finally, yet importantly, our in vitro analysis showed very high MIC values for fosfomycin for all isolates. This is in line with previous reports (Schröttner et al., 2017; Matos et al., 2019), making natural resistance very likely. Based on our in silico analysis, all isolates contained a gene homolog encoding for a potential MurA transferase with mutation conferring resistance to fosfomycin (Fu et al., 2015) (50.48\% identity) and for the fosfomycin modifying glutathione transferase FosC2 (Wachino et al., 2010) (26.62\% identity), among several other hits for efflux proteins. In addition, DSM 110473 carried with $62.67 \%$ identity a gene homologous to $m d t G$, which has been reported, when overexpressed, to increase fosfomycin resistances (Nishino and Yamaguchi, 2001). We strongly believe that $W$. chitiniclastica features a natural fosfomycin resistance, and maybe a yet unknown resistance mechanism might be present since no strong hits with high percentage identity were detected.

In conclusion, $W$. chitiniclastica has recently been described as a rare but potential new emerging human pathogen. However, with intensive usage of MALDI-TOF MS and 16S rRNA gene for identification, it might turn out that this species is even more common than currently anticipated. In case of infection, trimethoprim/sulfamethoxazole, levofloxacin, and cephalosporins, such as cefuroxime, may be the best antibiotics to use. Keeping in mind that exposure of many antibiotics lead to enormous selective pressures including resistome expansion (Wright, 2007), constant reevaluation is strongly recommended, in particular when updated EUCAST guidelines become available and/or new case studies are published. Further research is also required in order to identify genes or mutations that are responsible for antimicrobial resistance. The results of our in silico analysis could offer advantages in order to identify potential candidates for target specific manipulations, which will be a crucial component to unravel the genetic resistance profile of W. chitiniclastica.

\section{DATA AVAILABILITY STATEMENT}

The datasets presented in this study can be found in online repositories. The names of the repository/repositories and accession number(s) can be found below: https: //www.ncbi.nlm.nih.gov/genbank/, JAGIBR000000000; JAGIBS000000000; JAGIBT000000000; JAGIBU000000000; JAGIBV000000000; JAGIBW000000000; JAGIBX000000000; JAGIBY000000000; JAGIBZ000000000; JAGICA000000000; JAGICB000000000; JAGICC000000000; JAGICD000000000; JAGICE000000000.

\section{ETHICS STATEMENT}

The study was approved by the Ethics Committee at the Technical University of Dresden (EK 61022019). Written informed consent was not obtained from the individual(s) for the publication of any potentially identifiable images or data included in this article.

\section{AUTHOR CONTRIBUTIONS}

PS had the idea and the concept for the study. AK performed the experiments, analyzed the data, and wrote the first version of the manuscript. BB provided the bioinformatic data from the whole genome sequences. TR performed the curation of the bacteria and 
the inclusion into the DSMZ “Open Collection". BB, TR, SC, FG, and PS contributed text passages for the manuscript. All authors contributed to the revision of the manuscript and approved the present version.

\section{FUNDING}

This work was supported by the Federal Ministry of Education and Research, Germany (BMBF; ZIK Septomics Research Centre, Translational Septomics, award no. 03Z22JN12 to SC).

\section{REFERENCES}

Akdoğan, D., Güzel, M., Bahçe, Y. G., Aksoy, A., and Akpınar, O. (2021). Comparative antimicrobial susceptibility profiles of uropathogenic extendedspectrum Blactamase producing strains of Klebsiella pneumonia and Escherichia coli by the CLSI and EUCAST methodologies. Gazi Med. J. 32, 88-93. doi: 10.12996/GMJ.2021.16

Alcock, B. P., Raphenya, A. R., Lau, T. T. Y., Tsang, K. K., Bouchard, M., Edalatmand, A., et al. (2020). CARD 2020: antibiotic resistome surveillance with the comprehensive antibiotic resistance database. Nucleic Acids Res. 48, D517-D525. doi: 10.1093/nar/gkz935

Almuzara, M. N., Palombarani, S., Tuduri, A., Figueroa, S., Gianecini, A., Sabater, L., et al. (2011). First case of fulminant sepsis due to Wohlfahrtiimonas chitiniclastica. J. Clin. Microbiol. 49, 2333-2335. doi: 10.1128/JCM.00001-11

Altschul, S. F., Gish, W., Miller, W., Myers, E. W., and Lipman, D. J. (1990). Basic local alignment search tool. J. Mol. Biol. 215, 403-410. doi: 10.1016/S00222836(05)80360-2

Andersson, A. F., Lindberg, M., Jakobsson, H., Bäckhed, F., Nyrén, P., and Engstrand, L. (2008). Comparative analysis of human gut microbiota by barcoded pyrosequencing. PLoS One 3:e2836. doi: 10.1371/journal.pone. 0002836

Armougom, F. (2009). Exploring microbial diversity using 16S rRNA highthroughput methods. J. Comput. Sci. Syst. Biol. 2009, 74-92. doi: 10.4172/jcsb. 1000019

Bankevich, A., Nurk, S., Antipov, D., Gurevich, A. A., Dvorkin, M., Kulikov, A. S., et al. (2012). SPAdes: a new genome assembly algorithm and its applications to single-cell sequencing. J. Comput. Biol. 19, 455-477. doi: 10.1089/cmb.2012. 0021

Baranova, N., and Nikaido, H. (2002). The baeSR two-component regulatory system activates transcription of the yegMNOB (mdtABCD) transporter gene cluster in Escherichia coli and increases its resistance to novobiocin and deoxycholate. J. Bacteriol. 184, 4168-4176. doi: 10.1128/jb.184.15.4168-4176. 2002

Baym, M., Kryazhimskiy, S., Lieberman, T. D., Chung, H., Desai, M. M., and Kishony, R. (2015). Inexpensive multiplexed library preparation for megabasesized genomes. PLoS One 10:e0128036. doi: 10.1371/journal.pone.0128036

Benson, D. A., Cavanaugh, M., Clark, K., Karsch-Mizrachi, I., Lipman, D. J., Ostell, J., et al. (2013). GenBank. Nucleic Acids Res. 41, D36-D42. doi: 10.1093/nar/ gks1195

Berlau, J., Aucken, H., Malnick, H., and Pitt, T. (1999). Distribution of Acinetobacter species on skin of healthy humans. Eur. J. Clin. Microbiol. Infect. Dis. 18, 179-183. doi: 10.1007/s100960050254

Biller, S. J., Berube, P. M., Lindell, D., and Chisholm, S. W. (2015). Prochlorococcus: the structure and function of collective diversity. Nat. Rev. Microbiol. 13, 13-27. doi: $10.1038 /$ nrmicro3378

Bonwitt, J. H., Tran, M., Dykstra, E. A., Eckmann, K., Bell, M. E., Leadon, M., et al. (2018). Fly reservoir associated with wohlfahrtiimonas bacteremia in a human. Emerg. Infect. Dis. 24, 370-373. doi: 10.3201/eid2402.170913

Broecker, F., Klumpp, J., Schuppler, M., Russo, G., Biedermann, L., Hombach, M., et al. (2016). Long-term changes of bacterial and viral compositions in the intestine of a recovered Clostridium difficile patient after fecal microbiota transplantation. Cold Spring Harb. Mol. Case Stud. 2:a000448. doi: 10.1101/mcs. a000448

\section{ACKNOWLEDGMENTS}

We thank Franziska Burkhart and Stefan Tiede for excellent technical assistance.

\section{SUPPLEMENTARY MATERIAL}

The Supplementary Material for this article can be found online at: https://www.frontiersin.org/articles/10.3389/fmicb. 2021.712775/full\#supplementary-material

Bueide, P., Hunt, J., Bande, D., and Guerrero, D. M. (2021). Maggot wound therapy associated with wohlfahrtiimonas chitiniclastica blood infection. Cureus 13, 10-13. doi: 10.7759/cureus.12471

Campisi, L., Mahobia, N., and Clayton, J. J. (2015). Wohlfahrtiimonas chitiniclastica Bacteremia associated with Myiasis, United Kingdom. Emerg. Infect. Dis. 21, 1068-1069. doi: 10.3201/eid2106.1 40007

Cao, X.-M., Yan, Q.-L., Xu, B.-L., Chen, T., Zhang, X.-L., Wang, J., et al. (2013). Complete genome sequence of wohlfahrtiimonas chitiniclastica strain SH04, isolated from chrysomya megacephala collected from Pudong international airport in China. Genome Announc 1, 4-5. doi: 10.1128/genomea. 00119-13

Chakravorty, S., Helb, D., Burday, M., Connell, N., and Alland, D. (2007). A detailed analysis of $16 \mathrm{~S}$ ribosomal RNA gene segments for the diagnosis of pathogenic bacteria. J. Microbiol. Methods 69, 330-339. doi: 10.1016/j.mimet. 2007.02.005

Chavez, J. A., Alexander, A. J., Balada-Llasat, J. M., and Pancholi, P. (2017). A case of Wohlfahrtiimonas chitiniclastica bacteremia in continental United States. JMM Case Rep. 4, 10-12. doi: 10.1099/jmmcr.0.005134

Connelly, K., Freeman, E., Smibert, O., and Lin, B. (2019). Wohlfahrtiimonas chitiniclastica bloodstream infection due to a maggot-infested wound in a 54-year-old male. J. Glob. Infect. Dis. 11, 125-126. doi: 10.4103/jgid.jgid_58_18

Costea, P. I., Coelho, L. P., Sunagawa, S., Munch, R., Huerta-Cepas, J., Forslund, K., et al. (2017). Subspecies in the global human gut microbiome. Mol. Syst. Biol. 13:960. doi: 10.15252/msb.20177589

de Dios, A., Fisher, M. A., Dingle, T. C., Hamula, C. L., Tayal, A., and Jacob, S. (2015). First report of wohlfahrtiimonas chitiniclastica isolation from a patient with cellulitis in the United States. J. Clin. Microbiol. 53, 3942-3944. doi: 10. 1128/jcm.01534- 15

Eliopoulos, G. M., Maragakis, L. L., and Perl, T. M. (2008). Acinetobacter baumannii: epidemiology, antimicrobial resistance, and treatment options. Clin. Infect. Dis. 46, 1254-1263. doi: 10.1086/529198

Fang, L.-X., Chen, C., Cui, C.-Y., Li, X.-P., Zhang, Y., Liao, X.-P., et al. (2020). Emerging high-level tigecycline resistance: novel tetracycline destructases spread via the mobile tet(X). Bioessays 42:e2000014. doi: 10.1002/bies. 202000014

Fenwick, A. J., Arora, V., and Ribes, J. A. (2019). Wohlfahrtiimonas chitiniclastica: two clinical cases and a review of the literature. Clin. Microbiol. Newsl. 41, 33-38. doi: 10.1016/j.clinmicnews.2019.01.006

Fessler, A. T., Kadlec, K., and Schwarz, S. (2011). Novel apramycin resistance gene apmA in bovine and porcine methicillin-resistant Staphylococcus aureus ST398 isolates. Antimicrob. Agents Chemother. 55, 373-375. doi: 10.1128/AAC.0 1124-10

Fu, Z., Ma, Y., Chen, C., Guo, Y., Hu, F., Liu, Y., et al. (2015). Prevalence of fosfomycin resistance and mutations in murA, glpT, and uhpT in methicillinresistant staphylococcus aureus strains isolated from blood and cerebrospinal fluid samples. Front. Microbiol. 6:1544. doi: 10.3389/fmicb.2015.01544

Funke, G., Frod, R., and Sommer, H. (2004). First comprehensively documented case of Paracoccus yeei infection in a human. J. Clin. Microbiol. 42, 3366-3368. doi: 10.1128/JCM.42.7.3366-3368.2004

Gardiner, M., Vicaretti, M., Sparks, J., Bansal, S., Bush, S., Liu, M., et al. (2017). A longitudinal study of the diabetic skin and wound microbiome. PeerJ 2017:3543. doi: $10.7717 /$ peerj.3543 
Gardner, S. E., Hillis, S. L., Heilmann, K., Segre, J. A., and Grice, E. A. (2013). The neuropathic diabetic foot ulcer microbiome is associated with clinical factors. Diabetes 62, 923L-930L. doi: 10.2337/db12-0771

Haanperä, M., Jalava, J., Huovinen, P., Meurman, O., and Rantakokko-Jalava, K. (2007). Identification of alpha-hemolytic streptococci by pyrosequencing the 16S rRNA gene and by use of VITEK 2. J. Clin. Microbiol. 45, 762-770. doi: 10.1128/JCM.01342-06

Hedayatianfard, K., Akhlaghi, M., and Sharifiyazdi, H. (2014). Detection of tetracycline resistance genes in bacteria isolated from fish farms using polymerase chain reaction. Vet. Res. Forum Int. Q. J. 5, 269-275.

Hoffmann, R., Fortuin, F., Newton-Foot, M., and Singh, S. (2016). First report of Wohlfahrtiimonas chitiniclastica bacteraemia in South Africa. SAMJ South Afr. Med. J. 106:1062.

Hongoh, Y., Ohkuma, M., and Kudo, T. (2003). Molecular analysis of bacterial microbiota in the gut of the termite Reticulitermes speratus (Isoptera; Rhinotermitidae). FEMS Microbiol. Ecol. 44, 231-242. doi: 10.1016/S01686496(03)00026-6

Hu, Y., Zhang, W., Liang, H., Liu, L., Peng, G., Pan, Y., et al. (2011). Wholegenome sequence of a multidrug-resistant clinical isolate of Acinetobacter lwoffii. J. Bacteriol. 193, 5549-5550. doi: 10.1128/JB.05617-11

Johnson, J. S., Spakowicz, D. J., Hong, B. Y., Petersen, L. M., Demkowicz, P., Chen, L., et al. (2019). Evaluation of $16 \mathrm{~S}$ rRNA gene sequencing for species and strainlevel microbiome analysis. Nat. Commun. 10, 1-11. doi: 10.1038/s41467-01913036- 1

Kassim, A., Omuse, G., Premji, Z., and Revathi, G. (2016). Comparison of Clinical Laboratory Standards Institute and European Committee on Antimicrobial Susceptibility Testing guidelines for the interpretation of antibiotic susceptibility at a University teaching hospital in Nairobi, Kenya: a cross-sectional stud. Ann. Clin. Microbiol. Antimicrob. 15, 1-7. doi: 10.1186/ s12941-016-0135-3

Katanami, Y., Kutsuna, S., Nagashima, M., Takaya, S., Yamamoto, K., Takeshita, N., et al. (2018). Wohlfahrtiimonas chitiniclastica bacteremia hospitalized homeless man with squamous cell carcinoma. Emerg. Infect. Dis. 24, 1746-1748. doi: 10.3201/eid2409.170080

Klindworth, A., Peplies, J., Pruesse, E., Schweer, T., Glöckner, F. O., Quast, C., et al. (2012). Evaluation of general 16S ribosomal RNA gene PCR primers for classical and next-generation sequencing-based diversity studies. Nucleic Acids Res. 41:e1. doi: 10.1093/nar/gks808

Kobayashi, S., Kuzuyama, T., and Seto, H. (2000). Characterization of the fomA and fomB gene products from Streptomyces wedmorensis, which confer fosfomycin resistance on Escherichia coli. Antimicrob. Agents Chemother. 44, 647-650. doi: 10.1128/aac.44.3.647-650.2000

Kõljalg, S., Telling, K., Huik, K., Murruste, M., Saarevet, V., Pauskar, M., et al. (2015). First report of Wohlfahrtiimonas chitiniclastica from soft tissue and bone infection at an unusually high northern latitude. Folia Microbiol. (Praha) 60, 155-158. doi: 10.1007/s12223-014-0355-x

Ku, S. C., Hsueh, P. R., Yang, P. C., and Luh, K. T. (2000). Clinical and microbiological characteristics of bacteremia caused by acinetobacter lwoffii. Eur. J. Clin. Microbiol. Infect. Dis. 19, 501-505. doi: 10.1007/s100960000315

Lamas, A., Miranda, J. M., Regal, P., Vázquez, B., Franco, C. M., and Cepeda, A. (2018). A comprehensive review of non-enterica subspecies of Salmonella enterica. Microbiol. Res. 206, 60-73. doi: 10.1016/j.micres.2017.09.010

Lefort, V., Desper, R., and Gascuel, O. (2015). FastME 2.0: a comprehensive, accurate, and fast distance-based phylogeny inference program. Mol. Biol. Evol. 32, 2798-2800. doi: 10.1093/molbev/msv150

Levy, S. B., McMurry, L. M., Barbosa, T. M., Burdett, V., Courvalin, P., Hillen, W., et al. (1999). Nomenclature for new tetracycline resistance determinants. Antimicrob. Agents Chemother. 43, 1523-1524. doi: 10.1128/aac.43.6.1523

Lysaght, T. B., Wooster, M. E., Jenkins, P. C., and Koniaris, L. G. (2018). Myiasisinduced sepsis: a rare case report of Wohlfahrtiimonas chitiniclastica and Ignatzschineria indica bacteremia in the continental United States. Medicine (Baltimore) 97:e13627. doi: 10.1097/MD.0000000000013627

Matos, J., Faria, A. R., Carvalho Assef, A. P. D., de Freitas-Almeida, A. C., Albano, R. M., and Queiroz, M. L. P. (2019). Draft genome sequence of a wohlfahrtiimonas chitiniclastica strain isolated from frozen chicken in Rio De Janeiro, Brazil. Microbiol. Resour. Announc. 8, 1-2. doi: 10.1128/mra.00352-19

Mazurek, J., Bok, E., Stosik, M., and Baldy-Chudzik, K. (2015). Antimicrobial resistance in commensal Escherichia coli from pigs during metaphylactic trimethoprim and sulfamethoxazole treatment and in the post-exposure period. Int. J. Environ. Res. Public Health 12, 2150-2163. doi: 10.3390/ijerph120202150

Meier-Kolthoff, J. P., Auch, A. F., Klenk, H. P., and Göker, M. (2013a). Genome sequence-based species delimitation with confidence intervals and improved distance functions. BMC Bioinform. 14:60. doi: 10.1186/1471-2105-14-60

Meier-Kolthoff, J. P., and Göker, M. (2019). TYGS is an automated highthroughput platform for state-of-the-art genome-based taxonomy. Nat. Commun. 10:2182. doi: 10.1038/s41467-019-10210-3

Meier-Kolthoff, J. P., Göker, M., Spröer, C., and Klenk, H. P. (2013b). When should a DDH experiment be mandatory in microbial taxonomy? Arch. Microbiol. 195, 413-418. doi: 10.1007/s00203-013-0888-4

Meier-Kolthoff, J. P., Hahnke, R. L., Petersen, J., Scheuner, C., Michael, V., Fiebig, A., et al. (2014). Complete genome sequence of DSM 30083T, the type strain (U5/41T) of Escherichia coli, and a proposal for delineating subspecies in microbial taxonomy. Stand Genomic Sci. 9:2. doi: 10.1186/1944-3277-9-2

Mellmann, A., Cloud, J., Maier, T., Keckevoet, U., Ramminger, I., Iwen, P., et al. (2008). Evaluation of matrix-assisted laser desorption ionization-time-of-flight mass spectrometry in comparison to 16S rRNA gene sequencing for species identification of nonfermenting bacteria. J. Clin. Microbiol. 46, 1946-1954. doi: 10.1128/JCM.00157-08

Morán-Barrio, J., González, J. M., Lisa, M. N., Costello, A. L., Peraro, M. D., Carloni, P., et al. (2007). The metallo-beta-lactamase GOB is a mono- $\mathrm{Zn}$ (II) enzyme with a novel active site. J. Biol. Chem. 282, 18286-18293. doi: 10.1074/ jbc.M700467200

Naas, T., and Nordmann, P. (1994). Analysis of a carbapenem-hydrolyzing class A beta-lactamase from Enterobacter cloacae and of its LysR-type regulatory protein. Proc. Natl. Acad. Sci. U.S.A. 91, 7693-7697. doi: 10.1073/pnas.91.16. 7693

Nishino, K., Honda, T., and Yamaguchi, A. (2005). Genome-wide analyses of Escherichia coli gene expression responsive to the BaeSR two-component regulatory system. J. Bacteriol. 187, 1763-1772. doi: 10.1128/JB.187.5.17631772.2005

Nishino, K., and Yamaguchi, A. (2001). Analysis of a complete library of putative drug transporter genes in Escherichia coli. J. Bacteriol. 183, 5803-5812. doi: 10.1128/JB.183.20.5803-5812.2001

Nogi, M., Bankowski, M. J., and Pien, F. D. (2016). Wohlfahrtiimonas chitiniclastica infections in 2 elderly patients, Hawaii, USA. Emerg. Infect. Dis. 22, 567-568. doi: 10.3201/eid2203.151701

Nossa, C. W., Oberdorf, W. E., Yang, L., Aas, J. A., Paster, B. J., de Santis, T. Z., et al. (2010). Design of 16S rRNA gene primers for 454 pyrosequencing of the human foregut microbiome. World J. Gastroenterol. 16, 4135-4144. doi: 10.3748/wjg.v16.i33.4135

Park, K. S., Kim, T. Y., Kim, J. H., Lee, J. H., Jeon, J. H., Karim, A. M., et al. (2018). PNGM-1, a novel subclass B3 metallo- $\beta$-lactamase from a deep-sea sediment metagenome. J. Glob. Antimicrob. Resist. 14, 302-305. doi: 10.1016/j.jgar.2018. 05.021

Peleg, A. Y., Seifert, H., and Paterson, D. L. (2008). Acinetobacter baumannii: emergence of a successful pathogen. Clin. Microbiol. Rev. 21, 538-582. doi: 10.1128/CMR.00058-07

Perreten, V., and Boerlin, P. (2003). A new sulfonamide resistance gene (sul3) in Escherichia coli is widespread in the pig population of Switzerland. Antimicrob. Agents Chemother. 47, 1169-1172. doi: 10.1128/aac.47.3.1169-1172. 2003

Quast, C., Pruesse, E., Yilmaz, P., Gerken, J., Schweer, T., Yarza, P., et al. (2013). The SILVA ribosomal RNA gene database project: improved data processing and web-based tools. Nucleic Acids Res. 41, 590-596. doi: 10.1093/nar/gks 1219

Rebaudet, S., Genot, S., Renvoise, A., Fournier, P. E., and Stein, A. (2009). Wohlfahrtiimonas chitiniclastica bacteremia in homeless woman. Emerg. Infect. Dis. 15, 985-987. doi: 10.3201/eid1506.080232

Robbins, K., and Khachemoune, A. (2010). Cutaneous myiasis: a review of the common types of myiasis. Int. J. Dermatol. 49, 1092-1098. doi: 10.1111/j.13654632.2010.04577.x

Rudolph, W. W., Gunzer, F., Trauth, M., Bunk, B., Bigge, R., and Schröttner, P. (2019). Comparison of VITEK 2, MALDI-TOF MS, 16S rRNA gene sequencing, and whole-genome sequencing for identification of Roseomonas mucosa. Microb. Pathog. 134:103576. doi: 10.1016/j.micpath.2019.1 03576 
Schröttner, P., Gunzer, F., Schüppel, J., and Rudolph, W. W. (2016). Identification of rare bacterial pathogens by $16 \mathrm{~S}$ rRNA gene sequencing and MALDI-TOF MS. J. Vis. Exp. 2016:53176. doi: 10.3791/53176

Schröttner, P., Rudolph, W. W., Damme, U., Lotz, C., Jacobs, E., and Gunzer, S. (2017). Wohlfahrtiimonas chitiniclastica: current insights into an emerging human pathogen. Epidemiol. Infect. 145, 1292-1303. doi: 10.1017/ S0950268816003411

Schröttner, P., Rudolph, W. W., Eing, B. R., Bertram, S., and Gunzer, F. (2014). Comparison of VITEK2, MALDI-TOF MS, and 16S rDNA sequencing for identification of Myroides odoratus and Myroides odoratimimus. Diagn. Microbiol. Infect. Dis. 79, 155-159. doi: 10.1016/j.diagmicrobio.2014 .02 .002

Seifert, H., Dijkshoorn, L., Gerner-Smidt, P., Pelzer, N., Tjernberg, I., and Vaneechoutte, M. (1997). Distribution of Acinetobacter species on human skin: comparison of phenotypic and genotypic identification methods. J. Clin. Microbiol. 35, 2819-2825. doi: $10.1128 / \mathrm{jcm} .35 .11 .2819-2825$ .1997

Seng, P., Drancourt, M., Gouriet, F., Scola, B., Fournier, P. E., Rolain, J. M., et al. (2009). Ongoing revolution in bacteriology: routine identification of bacteria by matrix-assisted laser desorption ionization time-of-flight mass spectrometry. Clin. Infect. Dis. 49, 543-551. doi: 10.1086/600885

Snyder, S., Singh, P., and Goldman, J. (2020). Emerging pathogens: a case of Wohlfahrtiimonas chitiniclastica and Ignatzschineria indica bacteremia. IDCases 19:e00723. doi: 10.1016/j.idcr.2020.e00723

Spigaglia, P., Barbanti, F., Mastrantonio, P., Brazier, J. S., Barbut, F., Delmée, M., et al. (2008). Fluoroquinolone resistance in Clostridium difficile isolates from a prospective study of C. difficile infections in Europe. J. Med. Microbiol. 57, 784-789. doi: $10.1099 / \mathrm{jmm} .0 .47738-0$

Srinivasan, V. B., Vaidyanathan, V., Mondal, A., and Rajamohan, G. (2012). Role of the two component signal transduction system CpxAR in conferring cefepime and chloramphenicol resistance in Klebsiella pneumoniae NTUH-K2044. PLoS One 7:e33777. doi: 10.1371/journal.pone.0033777

Strejcek, M., Smrhova, T., Junkova, P., and Uhlik, O. (2018). Whole-cell MALDITOF MS versus $16 \mathrm{~S}$ rRNA gene analysis for identification and dereplication of recurrent bacterial isolates. Front. Microbiol. 9:1294. doi: 10.3389/fmicb.2018. 01294

Sune, D., Rydberg, H., Augustinsson, A. N., Serrander, L., and Jungeström, M. B. (2020). Optimization of $16 \mathrm{~S}$ rRNA gene analysis for use in the diagnostic clinical microbiology service. J. Microbiol. Methods 170:105854. doi: 10.1016/j.mimet. 2020.105854

Suraiya, S., Zuraina, N., Ahmad, F., and Rahman, Z. A. (2017). Fatal wohlfahrtiimonas chitiniclastica bacteremia in an immunocompromised patient. Clin. Microbiol. Newsl. 39, 172-173. doi: 10.1016/j.clinmicnews.2017. 07.003

Suryalatha, K., John, J., and Thomas, S. (2015). Wohlfahrtiimonas chitiniclasticaassociated osteomyelitis: a rare case report. Future Microbiol. 10, 1107-1109. doi: $10.2217 /$ fmb.15.44

Tatusova, T., DiCuccio, M., Badretdin, A., Chetvernin, V., Nawrocki, E. P., Zaslavsky, L., et al. (2016). NCBI prokaryotic genome annotation pipeline. Nucleic Acids Res. 44, 6614-6624. doi: 10.1093/nar/gk w569

Thaiwong, T., Kettler, N. M., Lim, A., Dirkse, H., and Kiupel, M. (2014). First report of emerging zoonotic pathogen Wohlfahrtiimonas chitiniclastica in the United States. J. Clin. Microbiol. 52, 2245-2247. doi: 10.1128/JCM.00 $382-14$

Timperio, A. M., Gorrasi, S., Zolla, L., and Fenice, M. (2017). Evaluation of MALDI-TOF mass spectrometry and MALDI BioTyper in comparison to $16 \mathrm{~S}$ rDNA sequencing for the identification of bacteria isolated from Arctic sea water. PLoS One 12:e181860. doi: 10.1371/journal.pone.0181860

Tóth, E. M., Schumann, P., Borsodi, A. K., Kéki, Z., Kovács, A. L., and Márialigeti, K. (2008). Wohlfahrtiimonas chitiniclastica gen. nov., sp. nov., a new gammaproteobacterium isolated from Wohlfahrtia magnifica (Diptera: sarcophagidae). Int. J. Syst. Evol. Microbiol. 58, 976-981. doi: 10.1099/ijs.0. 65324-0
Tringe, S. G., and Hugenholtz, P. (2008). A renaissance for the pioneering $16 \mathrm{~S}$ rRNA gene. Curr. Opin. Microbiol. 11, 442-446. doi: 10.1016/j.mib.2008.09.011

Tripathi, P. C., Gajbhiye, S. R., and Agrawal, G. N. (2014). Clinical and antimicrobial profile of Acinetobacter spp.: an emerging nosocomial superbug. Adv. Biomed. Res. 3:13. doi: 10.4103/2277-9175.124642

Truong, D. T., Tett, A., Pasolli, E., and Huttenhower, C. (2015). IMicrobial strainlevel population structure and genetic diversity from metagenomes. ISME J. 9, 68-80. doi: 10.1101/gr.216242.116.Freely

Wachino, J., Yamane, K., Suzuki, S., Kimura, K., and Arakawa, Y. (2010). Prevalence of fosfomycin resistance among CTX-M-producing Escherichia coli clinical isolates in Japan and identification of novel plasmid-mediated fosfomycin-modifying enzymes. Antimicrob. Agents Chemother. 54, 3061-3064. doi: 10.1128/AAC.01834-09

Walkty, A., Boyd, D. A., Gravel, D., Hutchinson, J., McGeer, A., Moore, D., et al. (2010). Molecular characterization of moxifloxacin resistance from Canadian Clostridium difficile clinical isolates. Diagn. Microbiol. Infect. Dis. 66, 419-424. doi: 10.1016/j.diagmicrobio.2009.12.002

Wang, Y., and Qian, P.-Y. (2009). Conservative fragments in bacterial 16S rRNA genes and primer design for $16 \mathrm{~S}$ ribosomal DNA amplicons in metagenomic studies. PLoS One 4:e7401. doi: 10.1371/journal.pone.0007401

Wayne, P. C., and Clinical and Laboratory Standards Institute (CLSI) (2016). CLSI. Methods for Antimicrobial Dilution and Disk Susceptibility Testing of Infrequently Isolated or Fastidious Bacteria. CLSI Guideline M45, 3rd Edn. Pittsburgh, PA: CLSI.

Weisburg, W. G., Barns, S. M., Pelletier, D. A., and Lane, D. J. (1991). 16S ribosomal DNA amplification for phylogenetic study. J. Bacteriol. 173, 697-703.

Welch, T. J., Fricke, W. F., McDermott, P. F., White, D. G., Rosso, M.-L., Rasko, D. A., et al. (2007). Multiple antimicrobial resistance in plague: an emerging public health risk. PLoS One 2:e309. doi: 10.1371/journal.pone.0000309

Wolcott, R. D., Hanson, J. D., Rees, E. J., Koenig, L. D., Phillips, C. D., Wolcott, R. A., et al. (2016). Analysis of the chronic wound microbiota of 2,963 patients by $16 \mathrm{~S}$ rDNA pyrosequencing. Wound Repair Regen. 24, 163-174. doi: 10.1111/ wrr. 12370

Wright, G. D. (2007). The antibiotic resistome: the nexus of chemical and genetic diversity. Nat. Rev. Microbiol. 5, 175-186. doi: 10.1038/nrmicro1614

Yokoyama, K., Doi, Y., Yamane, K., Kurokawa, H., Shibata, N., Shibayama, K., et al. (2003). Acquisition of $16 \mathrm{~S}$ rRNA methylase gene in Pseudomonas aeruginosa. Lancet (London, England) 362, 1888-1893. doi: 10.1016/S0140-6736(03) 14959-8

Yum, S., Xu, Y., Piao, S., Sim, S.-H., Kim, H.-M., Jo, W.-S., et al. (2009). Crystal structure of the periplasmic component of a tripartite macrolide-specific efflux pump. J. Mol. Biol. 387, 1286-1297. doi: 10.1016/j.jmb.2009.02.048

Zhou, W., Li, M., Zhu, L., Hua, F., Ji, X., Sun, Y., et al. (2016). Complete genome sequence of Wohlfahrtiimonas chitiniclastica strain BM-Y, isolated from the pancreas of a zebra in China. Genome Announc 4, 2015-2016. doi: 10.1128/ genomeA.00643-16

Conflict of Interest: The authors declare that the research was conducted in the absence of any commercial or financial relationships that could be construed as a potential conflict of interest.

Publisher's Note: All claims expressed in this article are solely those of the authors and do not necessarily represent those of their affiliated organizations, or those of the publisher, the editors and the reviewers. Any product that may be evaluated in this article, or claim that may be made by its manufacturer, is not guaranteed or endorsed by the publisher.

Copyright ( 2021 Kopf, Bunk, Coldewey, Gunzer, Riedel and Schröttner. This is an open-access article distributed under the terms of the Creative Commons Attribution License (CC BY). The use, distribution or reproduction in other forums is permitted, provided the original author(s) and the copyright owner(s) are credited and that the original publication in this journal is cited, in accordance with accepted academic practice. No use, distribution or reproduction is permitted which does not comply with these terms. 